\title{
Polarimetric remote sensing in oxygen $A$ and $B$ bands: sensitivity study and information content analysis for vertical profile of aerosols
}

\author{
Shouguo Ding ${ }^{1, a}$, Jun Wang ${ }^{1}$, and Xiaoguang $\mathrm{Xu}^{1}$ \\ ${ }^{1}$ Department of Earth and Atmospheric Sciences, University of Nebraska Lincoln, Lincoln, NE 68588, USA \\ ${ }^{a}$ now at: Earth Resources Technological Inc., Laurel, MD 20707, USA \\ Correspondence to: Jun Wang (jwangjun@gmail.com)
}

Received: 5 November 2015 - Published in Atmos. Meas. Tech. Discuss.: 18 January 2016

Revised: 18 April 2016 - Accepted: 25 April 2016 - Published: 11 May 2016

\begin{abstract}
Theoretical analysis is conducted to reveal the information content of aerosol vertical profile in space-borne measurements of the backscattered radiance and degree of linear polarization (DOLP) in oxygen $\left(\mathrm{O}_{2}\right) \mathrm{A}$ and $\mathrm{B}$ bands. Assuming a quasi-Gaussian shape for aerosol vertical profile characterized by peak height $H$ and half width $\gamma$ (at half maximum), the Unified Linearized Vector Radiative Transfer Model (UNL-VRTM) is used to simulate the Stokes fourvector elements of upwelling radiation at the top of atmosphere (TOA) and their Jacobians with respect to $H$ and $\gamma$. Calculations for different aerosol types and different combinations of $H$ and $\gamma$ values show that the wide range of gas absorption optical depth in $\mathrm{O}_{2} \mathrm{~A}$ and $\mathrm{B}$ band enables the sensitivity of backscattered DOLP and radiance at TOA to the aerosol layer at different altitudes. Quantitatively, DOLP in $\mathrm{O}_{2} \mathrm{~A}$ and $\mathrm{B}$ bands is found to be more sensitive to $H$ and $\gamma$ than radiance, especially over the bright surfaces (with large visible reflectance). In many $\mathrm{O}_{2}$ absorption wavelengths, the degree of freedom of signal (DFS) for retrieving $H$ (or $\gamma$ ) generally increases with $H$ (and $\gamma$ ) and can be close to unity in many cases, assuming that the composite uncertainty from surface and aerosol scattering properties as well as measurements is less than $5 \%$. Further analysis demonstrates that DFS needed for simultaneous retrieval of $H$ and $\gamma$ can be obtained from a combined use of DOLP measurements at $\sim 10-100 \mathrm{O}_{2} \mathrm{~A}$ and $\mathrm{B}$ absorption wavelengths (or channels), depending on the specific values of $H$. The higher the aerosol layer, the fewer number of channels for DOLP measurements in $\mathrm{O}_{2} \mathrm{~A}$ and $\mathrm{B}$ bands are needed for characterizing $\mathrm{H}$ and $\gamma$. Future hyperspectral measurements of DOLP in $\mathrm{O}_{2} \mathrm{~A}$ and $\mathrm{B}$ bands are needed to continue studying their potential and their combination with radiance and DOLP in atmo-
\end{abstract}

spheric window channels for retrieving the vertical profiles of aerosols, especially highly scattering aerosols, over land.

\section{Introduction}

Aerosols are ubiquitous in the atmosphere and play an important role in the climate system through their direct effects on the transfer of radiative energy (Forster et al., 2007) and indirect effects on cloud microphysical properties by serving as cloud condensation nuclei (Twomey, 1977). These effects of aerosols are considered to be one of the largest uncertainty sources to estimate and interpret the Earth's changing energy budget (IPCC, 2013). The climatic effects of aerosols are highly sensitive to the variation of aerosol optical and physical properties, not only in the horizontal but also in the vertical dimension. Information on aerosol vertical distribution is essential for providing a clear description of aerosol transport processes (Colarco et al., 2004), as well as for understanding how radiative energy and clouds in the atmosphere are affected by aerosols (Wang et al., 2004, 2009). Consequently, the vertical distribution of aerosols affects the sign and magnitude of regional temperature change due to global warming (Haywood and Shine, 1997; Meloni et al., 2005; Zarzycki and Bond, 2010; Samset and Myhre, 2011; Samset et al., 2013), the precipitation patterns (Huang et al., 2009) and air quality and visibility (Liu et al., 2011; Kessner et al., 2013).

Because aerosols are highly variable in space and time, the only way to measure aerosol vertical distribution on a global scale is by means of satellite remote sensing. Using lidar, such as the Cloud-Aerosol Lidar Infrared Pathfinder Satel- 
lite Observations (CALIPSO) (Vaughan et al., 2004; Hunt et al., 2009), is a direct method to probe the vertical structure of aerosols in cloud-free conditions. However, the active remote sensing of aerosols with lidar is expensive and its narrow swath limits the spatial coverage. For example, CALIPSO flies over a given site only once every 16 days (Winker, 2003). Most passive satellite-based measurements in ultraviolet and/or visible bands, such as those from the Multi-angle Imaging SpectroRadiometer (MISR), the Ozone Monitoring Instrument (OMI) (Levelt et al., 2006) and the Polarization and Directionality of the Earth's Reflectance (POLDER) (Deschamps et al., 1994; Tanré et al., 2011), contain limited vertical information of aerosols beyond the aerosol optical depth (AOD), a columnar quantity. Only with additional constraints (such as aerosol single scattering albedo and AOD) from independent sources can OMI measurements be used to derive the centroid height of a highly elevated absorbing aerosol layer (Satheesh et al., 2009). It is also noted that multi-angle instrument such as MISR can be used to derive the stereo height of an aerosol layer, although such derivation is not based on the particle scattering and radiative transfer calculations (Kahn et al., 2007).

In the last decade, various studies have proposed methods for the passive remote sensing of aerosol vertical profile from space using measurements in the $\mathrm{O}_{2}$ A band (760-775 nm), such as those from the Global Ozone Monitoring Experiment (GOME) (Koppers and Murtagh, 1997) and the SCanning Imaging Absorption spectroMeter for Atmospheric CHartographY (SCIAMACHY) (Corradini and Cervino, 2006; Sanghavi et al., 2012). $\mathrm{O}_{2}$ A (755-775 nm) and $\mathrm{O}_{2} \mathrm{~B}(685-695 \mathrm{~nm})$ bands are the two absorption spectrum introduced by the change of oxygen electronic energy levels through vibrational-rotational transitions and molecular collision in the atmosphere (Goody and Yung, 1989). The underlying fundament physical principle is that $\mathrm{O}_{2}$ is a well-mixed gas in the atmosphere with well-defined vertical structure, and hence, assuming other factors being equal, the change in the amount of upwelling radiation in the $\mathrm{O}_{2} \mathrm{~A}$ band contains information about how aerosol particles affect $\mathrm{O}_{2} \mathrm{~A}$ absorption through multiple scattering in different altitudes. Indeed, this idea dates back to Hanel (1961) and Yamamoto and Wark (1961), who are among the first to study the retrieval of cloud top pressure from reflection spectra in the $\mathrm{O}_{2}$ A band, although cloud particles are larger and more efficient in scattering and, therefore, have bigger impact on radiative transfer in the $\mathrm{O}_{2} \mathrm{~A}$ band than aerosol particles. Following their pioneer work, a wealth of literature has developed and evaluated the techniques to retrieve cloud top height from $\mathrm{O}_{2}$ A band in the last 4 decades (Grechko et al., 1973; Mitchell and O'Brien, 1987; Fischer and Grassl, 1991; Fischer et al., 1991; O'Brien and Mitchell, 1992; Harrison and Min, 1997; Pfeilsticker et al., 1998). In contrast, studies on the feasibility of retrieving aerosol vertical profile form $\mathrm{O}_{2}$ A band were conducted primarily in the last decade (Heidinger and Stephens, 2000; Min et al., 2004; van Diedenhoven et al.,
2007; Kokhanovsky and Rozanov, 2004; Daniel et al., 2003; Sanghavi et al., 2012; Corradini and Cervino, 2006; Koppers and Murtagh, 1997; Dubuisson et al., 2009). These studies showed that the radiance at the top of atmosphere (TOA) in the $\mathrm{O}_{2} \mathrm{~A}$ band contain information on the vertical structure of aerosol scattering, and this information can only be retrieved in clear skies over sufficiently dark surfaces such as ocean away from glint. Hence, retrieving aerosol profiles over land still remains a challenge because land surface reflectance is often much higher in the $\mathrm{O}_{2} \mathrm{~A}$ band than in the ultraviolet and blue wavelengths.

The objective of this study is to systematically study the information content of aerosol vertical profile from a combined use of polarization and radiance measurements in the $\mathrm{O}_{2} \mathrm{~A}$ and $\mathrm{B}$ bands. The underlying motivation is that the surface polarized reflectance is generally low (Maignan et al., 2009) and, hence, using polarization in $\mathrm{O}_{2} \mathrm{~A}$ and $\mathrm{B}$ bands may provide a unique opportunity to retrieve aerosol vertical profile over not only dark but also bright surfaces (such as desert and urban regions). Stam et al. (1999) investigated the degree of linear polarization (DOLP) of reflected and transmitted light in the $\mathrm{O}_{2}$ A band for a few typical atmospheric profiles and identified different regimes of DOLP based on the gas absorption optical depth. Aben et al. (1999) presented that the polarization measurements in the $\mathrm{O}_{2} \mathrm{~A}$ band in clear sky contain rich spectral fine structure. This fine structure is shown to contain information of vertical distribution of aerosols by various modeling studies (Preusker et al., 1995; Boesche et al., 2006, 2009; Zeng et al., 2008). Most recently, Wang et al. (2014) showed that the DOLP in the $\mathrm{O}_{2} \mathrm{~A}$ band has higher sensitivity to the vertical profile of aerosols than that of intensity, especially over the high reflective surface. In this study, we carry out further sensitivity analysis to assess the potential for retrieving aerosol vertical profile by considering the polarization in both $\mathrm{O}_{2} \mathrm{~A}$ and $\mathrm{B}$ bands. While theoretical, the assessment here can have important implications to aerosol algorithm development for the recent deployment of wide-swath satellite sensors as the Earth Polychromatic Imaging Camera (EPIC) on Deep Space Climate Observatory (DSCOVR) that measures radiance in both $\mathrm{O}_{2} \mathrm{~A}$ and $\mathrm{B}$ bands (http://epic.gsfc.nasa.gov/epic.html), as well as for future satellite missions such as Pre-Aerosol, Clouds, and ocean Ecosystem (PACE) that may have the opportunity to have a polarimeter (http://decadal.gsfc.nasa.gov/ pace-resources.html).

Our study is different from the past studies in two main ways. First, to investigate the effects of various aerosols on DOLP at hyperspectral resolution under different surface conditions, we not only focus on the analysis in the $\mathrm{O}_{2} \mathrm{~A}$ but also extend the analysis to include the $\mathrm{O}_{2} \mathrm{~B}$ band. While Sanghavi et al. (2012) and Vasilkov et al. (2013) have demonstrated that radiance in $\mathrm{O}_{2} \mathrm{~A}$ and $\mathrm{B}$ bands can be used for retrieving aerosol profile over dark surfaces, this study is the first to test whether a combined use of DOLP in these bands can add information over visibly bright surfaces. Sec- 
ond, our analysis of information content is conducted to recommend the most informative channels for the design of future sensors that will measure the polarization in $\mathrm{O}_{2} \mathrm{~A}$ and $\mathrm{B}$ bands. Indeed, except for a Fourier transform spectrometer (TANSO-FTS) aboard the Japanese Greenhouse Gases Observing Satellite (GOSAT) that is capable of measuring twoorthogonal polarizations in $\mathrm{O}_{2}$ A band (Kuze et al., 2009), few satellite sensors measure the state of polarization in $\mathrm{O}_{2}$ $\mathrm{A}$ and $\mathrm{B}$ bands at hyperspectral resolution with a primary aim for retrieving aerosols. Furthermore, existing routine measurements of polarization spectra in $\mathrm{O}_{2}$ A band taken by polarimetric instruments (such as those aboard on GOME-2 and SCIAMACHY) are primarily used to improve radiometric calibration. We note that satellite spectrometers such as GOME-2, SCIAMACHY, and GOSAT have a large number of spectral channels, but not all of them are necessary for operational retrievals. Hence, under cost constraints, if we want to measure polarization in both $\mathrm{O}_{2} \mathrm{~A}$ and $\mathrm{B}$ bands with a wide spatial coverage and high spatial resolution (unlike GOSAT with narrow swath or GOME-2 with big footprint), it is important to answer the following question: at which spectra should these measurements be taken to maximize the information content for aerosol vertical distribution?

To pursuit the objectives above, we first use a rigorous radiative transfer model, the Unified Linearized Vector Radiative Transfer Model (UNL-VRTM) (Wang et al., 2014), to simulate the Stokes elements and their Jacobians with respect to the aerosol optical and physical parameters, in both $\mathrm{O}_{2} \mathrm{~A}$ and B bands at hyperspectral resolution. Subsequently, the analysis of information content is conducted at hyperspectral resolution based on the optimal estimation theory (Rodgers, 2000), which allows us to identify the most useful channels for retrieving the aerosol vertical profile. We use the degree of freedom of signal (DFS) to describe the sensitivities of individual wavelengths in both $\mathrm{O}_{2} \mathrm{~A}$ and $\mathrm{B}$ bands to the aerosol vertical profile and select the combination of most sensitive wavelengths. DFS is a variable that can quantify the number of useful independent pieces of information in the measurement for retrieving the corresponding parameter(s) of our interest (Rodgers, 2000).

In Sect. 2, we outline the theoretical basis of this study including the introduction of UNL-VRTM and the optimization strategy used for the information content analysis. In Sect. 3, we discuss the sensitivities of DOLP and intensity in both $\mathrm{O}_{2} \mathrm{~A}$ and $\mathrm{B}$ bands to the aerosol profiles in terms of DFS, and we present the results about the potential of retrieving the aerosol vertical profile (aerosol peak height and half width at half maximum, simultaneously) with multiple channels in $\mathrm{O}_{2} \mathrm{~A}$ and $\mathrm{B}$ bands. The summaries and conclusions follow in Sect. 4.

\section{Description of methods and computations}

\subsection{Definition of DOLP}

The degree of polarization (DOP) is a quantity that describes partially polarized light (Chandrasekhar, 1950). It is defined as the ratio between the intensity of the totally polarized component to the total intensity of the light:

$\mathrm{DOP}=\frac{\sqrt{Q^{2}+U^{2}+V^{2}}}{I}$,

where the Stokes parameter $I$ describes the total intensity, $Q$ and $U$ the linear polarization and $V$ the circular polarization of the light beam. Since the reflection of sunlight by natural surfaces and atmospheric scattering generates very weak elliptic polarization (Coulson, 1988), $V$ is negligibly small compared to the other three parameters. The DOLP of light can be given as

DOLP $=\frac{\sqrt{Q^{2}+U^{2}}}{I}$.

For skylight measurements within the principal plane, $U=0$. To preserve the sign of $Q$, the DOLP in principal plane can be written as (Hovenier et al., 2004)

$\mathrm{DOLP}=-\frac{Q}{I}$

\subsection{Forward radiative transfer model}

A numerical test bed, the UNL-VRTM (Wang et al., 2014), is used in the present study. The UNL-VRTM comprises the following several modules:

- a linearized vector radiative transfer model (VLIDORT; Spurr, 2006), which computes simultaneously the Stokes four-vector elements and their Jacobians with respect to various atmospheric and surface properties (Spurr et al., 2008), including aerosol single scattering properties at different layers and as a column, as well as the aerosol height (Wang et al., 2014);

- a linearized Mie scattering code (Spurr et al., 2012), which computes the optical properties of spherical aerosol particles and their Jacobians with respect to aerosol physical parameters such as refractive index and particle size distribution;

- a linearized T-matrix electromagnetic scattering code (Spurr et al., 2012), which works similarly to the linearized Mei code, but for nonspherical aerosols;

- a surface bi-directional reflectance and polarization function module (Spurr, 2004), which provide surface bi-directional reflectance and the Jacobians with respect to kernel parameters; 
- a module that computes both Rayleigh scattering and gas absorption with HITRAN database (Rothman et al., 2013) to provide the optical thickness of atmospheric molecule scattering and absorption, respectively. Wang et al. (2014) have validated the calculations of Jacobians of $[I, Q, U]$ with respect to the aerosol physical parameters such as refractive index, particle size distribution and aerosol height. With UNL-VRTM, Xu and Wang (2015) and Xu et al. (2015) studied the information content of the ground-based photopolarimetric measurements of sky light and developed an algorithm for the retrieval of fine-mode and coarse-mode aerosol microphysical parameters.

\subsection{Aerosol vertical profile}

Various shapes of aerosol vertical profile can be defined in UNL-VRTM including uniform, exponentially decreasing and quasi-Gaussian shapes. Since our main purpose is to study the sensitivity of the DOLP and intensity to aerosol vertical distribution, we select the quasi-Gaussian profile (Spurr and Christi, 2014). The optical depth profile is given by

$$
\tau_{A}(z)=C \frac{\exp (-h|z-H|)}{[1+\exp (-h|z-H|)]^{2}},
$$

where $C$ is a constant related to the total optical depth and $h$ is related to the half width $(\gamma)$ at the half maximum (of AOD), which is defined as $\gamma=\frac{\ln (3+\sqrt{8})}{h} . H$ is the peak height or the altitude at which the aerosol extinction is the largest.

\subsection{Information content and DFS}

The relationship between the measurement vector $\boldsymbol{y}$ (such as DOLP and intensity in $\mathrm{O}_{2}$ A band) and the state vector $\boldsymbol{x}$ (such as aerosol parameters and aerosol vertical profile) to be retrieved can be given by

$\boldsymbol{y}=\mathbf{F}(\boldsymbol{x})+\boldsymbol{\varepsilon}$,

where $\mathbf{F}(\boldsymbol{x})$ is a forward model and $\boldsymbol{\varepsilon}$ is the measurement error.

For the purpose of examining the information content of a measurement, it is convenient to consider a linear problem or divide a nonlinear process into linear sub-processes. A linearization of the forward model at a reference state $\boldsymbol{x}_{0}$ will be adequate for this purpose, provided that $\mathbf{F}(\mathbf{x})$ is linear within the error bounds of the retrieval:

$\boldsymbol{y}-\mathbf{F}\left(\boldsymbol{x}_{0}\right)=\frac{\partial \mathbf{F}(\boldsymbol{x})}{\partial \boldsymbol{x}}\left(\boldsymbol{x}-\boldsymbol{x}_{0}\right)+\boldsymbol{\varepsilon}=\mathbf{K}\left(\boldsymbol{x}-\boldsymbol{x}_{0}\right)+\boldsymbol{\varepsilon}$,

where $\boldsymbol{x}_{0}$ defines a linearization point or the a priori information. With the Bayesian approach assuming Gaussian distribution for measurement and a priori errors, Rodgers (2000) showed that the retrieval uncertainty (the a posteriori covariance matrix $\mathbf{S}$ ) is relevant to the Jacobian $\mathbf{K}$ :

$\mathbf{S}^{-1}=\mathbf{K}^{T} \mathbf{S}_{\varepsilon}^{-1} \mathbf{K}+\mathbf{S}_{\mathrm{a}}^{-1}$,

where $\mathbf{S}_{\varepsilon}$ is the measurement error covariance matrix and $\mathbf{S}_{\mathrm{a}}$ is the a priori error covariance matrix. To obtain the link between the retrieval and the true state, the averaging kernel matrix $\mathbf{A}$ is introduced, which is defined as

$\mathbf{A}=\left(\mathbf{K}^{\mathbf{T}} \mathbf{S}_{\varepsilon}^{-1} \mathbf{K}+\mathbf{S}_{\mathrm{a}}^{-1}\right)^{-\mathbf{1}} \mathbf{K}^{T} \mathbf{S}_{\varepsilon}^{-1} \mathbf{K}$.

The trace of $\mathbf{A}$ is called the DFS, which describes the number of useful independent pieces of information in the measurement for the retrieval and hence is a measure of information content to infer a posteriori state vector. For each single retrieval variable, the value of DFS is between 0 and 1 . If DFS for one aerosol parameter is close to 0 , it indicates that the measurements have no information for the retrieval of that parameter. In our following sensitivity study, the measurement error is assumed to be 0.05 (absolute error) for DOLP and relative error of 0.05 (or $5 \%$ ) for intensity, following our past work (Xu and Wang, 2015). The a priori error is assumed to be $100 \%$ for both aerosol peak height and half width. Note, the measurement error here includes the errors from instrument error and radiative transfer modeling error (due to the uncertainty in AOD and aerosol optical properties). Increase of measurement error does lead to the decrease of DFS for the retrieval parameters and some discussions on this are given in the end of Sect. 3.

\subsection{Design of sensitivity experiments}

Three types of experiments are conducted to analyze

a. the sensitivity of DOLP and radiance of scattered sunlight at the TOA to the aerosol peak height $H$ over various surface types, assuming $\gamma$ (the half width at half maximum) is well known;

b. the sensitivity of DOLP and radiance to $\gamma$ over various surface conditions, assuming that the aerosol peak height is well known;

c. the sensitivity of DOLP and radiance to both $H$ and $\gamma$.

We conducted these experiments for several types of aerosols listed in Table 1, i.e., strongly absorbing (such as soot), moderately absorbing (such as dust) and strongly scattering aerosols (such as sulfate). For the purpose of simplicity, we present results for moderate absorbing (dust) aerosols in detail. Results for other types of aerosols are highlighted as sensitivity analysis in the last part of the results section (Sect. 3.4). In this paper, dust aerosols are assumed as spherical with lognormal size distribution with median radius and geometric standard deviation of $0.4 \mu \mathrm{m}$ and 0.61 , respectively (or equivalent to $r_{\text {eff }}=1 \mu \mathrm{m}$ and effective variance $v_{\text {eff }}=0.45$; Hansen and Travis, 1974), and with refractive index of 1.53-0.008 $i$ in the $\mathrm{O}_{2} \mathrm{~A}$ and $\mathrm{B}$ bands. While 
Table 1. The microphysical and optical properties of aerosols used in the simulations*.

\begin{tabular}{llll}
\hline Type & $R_{\mathrm{g}}(\mu \mathrm{m})$ & $\sigma_{\mathrm{g}}$ & Refractive index \\
\hline Dust & 0.40 & 0.61 & $1.53-0.008 i$ \\
Sulfate & 0.20 & 0.61 & $1.428-2.05 \times 10^{-8} i$ \\
Soot & 0.08 & 0.31 & $1.75-0.43 i$
\end{tabular}

* The size distribution is described with log-normal distribution function with $R_{\mathrm{g}}$ and $\sigma_{\mathrm{g}}$ representing median radius and geometric standard deviation as in Hansen and Travis (1974).

ambient dust particles are often nonspherical, spherical dust particles or coarse-mode spherical particles were also observed in the atmosphere (Wang et al., 2003). Our treatment of dust particles as spherical is not ideal, and this non-ideality is primarily due to the difficulties of linearized T-matrix technique for computing scattering properties of large particles (Wang et al., 2014; Xu and Wang, 2015). Our future studies will use the database of aerosol properties for nonspherical particles complied by past studies (e.g., Meng et al., 2010) to derive the Jacobins of aerosol single scattering properties with respect to aerosol size and refractive index parameters through finite difference method and to integrate these Jacobins databases into UNL-VRTM.

The information content of measurements in each experiment is characterized in terms of DFS for $\mathrm{O}_{2} \mathrm{~A}, \mathrm{O}_{2} \mathrm{~B}$ and combined $\mathrm{O}_{2} \mathrm{~A}$ and $\mathrm{O}_{2} \mathrm{~B}$ bands. Each experiment is also carried out for a set of different aerosol profiles in which the aerosol peak heights are assumed to range from 1 to $16 \mathrm{~km}$ with increment of $1 \mathrm{~km}$ and the aerosol half width is assumed to be 0.25 to $4 \mathrm{~km}$ with increment of $0.25 \mathrm{~km}$. All the simulations are conducted for principal plane at the spectral resolution of $0.01 \mathrm{~nm}$.

\section{Results}

\subsection{Gas absorption optical depth in $\mathrm{O}_{2} \mathrm{~A}$ and $\mathrm{B}$ bands}

Figure 1a-b show the spectral absorption optical depth in $\mathrm{O}_{2}$ $\mathrm{A}$ and $\mathrm{B}$ bands for a typical midlatitude summer atmosphere (McClatchey et al., 1972). The maximum absorption optical depth can reach 100 and 7 in the $\mathrm{O}_{2} \mathrm{~A}$ and $\mathrm{B}$ bands, respectively. Therefore, the sunlight can be fully attenuated before it reaches the surface at wavelengths of strong $\mathrm{O}_{2}$ absorption. The large variability of absorption optical depth in the $\mathrm{O}_{2} \mathrm{~A}$ and $\mathrm{B}$ bands enables sunlight from the TOA to penetrate the atmosphere at different depths (before it completely attenuated in the atmosphere; Fig. 1c-d). For instance, the penetration altitude is about $30 \mathrm{~km}$ above the surface in the center of $\mathrm{O}_{2} \mathrm{~A}$ band and decreases to $20 \mathrm{~km}, 10 \mathrm{~km}$ and near the surface as the wavelength moves from the center to the edge of $\mathrm{O}_{2} \mathrm{~A}$ band (Fig. 1c). Similarly, for wavelengths at the $\mathrm{O}_{2} \mathrm{~B}$ band, the penetration altitude can vary from $15 \mathrm{~km}$ to the surface depending on the wavelength (Fig. 1d). Hence, for a given atmospheric profile with well-characterized vertical profile of $\mathrm{O}_{2}$ absorption, the spectral contrast of reflected sunlight in terms of their intensity and polarization in these bands contains information of atmospheric scattering (including aerosol scattering) at different altitudes of the atmosphere.

To quantitatively illustrate the sensitivity of backscattered intensity and polarization with respect to the vertical profile of scattering, we first conduct the UNL-VRTM calculation for aerosol-free conditions. Considering that the absorption optical depth highly varies with wavelength in both $\mathrm{O}_{2}$ A and B bands, we plot in Fig. 1e-f the DOLP at the top of an aerosol-free atmosphere over various surface types (with albedo $A_{\mathrm{s}}$ of $0.0,0.05,0.2$ and 0.5 ) as a function of $\mathrm{O}_{2}$ absorption depth. It should be noted that the $\mathrm{O}_{2}$ absorption (often larger than 1) is much larger than the Rayleigh scattering optical depth (0.026-0.024 and 0.040-0.037, respectively) in $\mathrm{O}_{2} \mathrm{~A}$ and $\mathrm{B}$ bands, and hence the spectral variation of DOLP in these bands has visually no dependence on spectral variation of Rayleigh optical depth (figures now shown). As shown in Fig. 1e-f, the magnitude of $\mathrm{O}_{2}$ absorption optical depth and its effect on DOLP can be categorized into the following three distinct regions.

The first region has the gaseous absorption optical depth less than 0.1. Because of the strong interaction between atmospheric scattering and surface reflection (with $A_{\mathrm{s}}>0$ ), DOLP is less than $20 \%$ when absorption optical depth is very small (for example $\ll 0.1$ ) in Fig. 1e-f. As surface reflectance increases from 0.05 (grey line) to 0.2 (blue line), the DOLP decreases because the stronger multiple scattering occurring between the surface and atmosphere decreases the DOLP. Indeed, DOLP is nearly 0 when surface reflectance is very high $\left(A_{\mathrm{S}}\right.$ of 0.5$)$. However, when surface is black $\left(A_{\mathrm{s}}=0\right)$, DOLP is a result of the Rayleigh scattering only (as $\mathrm{O}_{2}$ optical depth $\ll 0.1$ ) and therefore is the largest (up to $57 \%)$.

The second region has the gaseous absorption optical depth larger than 20. The DOLP in this region is mainly determined by scattering in the upper atmospheric layer where molecular scattering dominates and leads to larger DOLP (up to $57 \%$ ) regardless of the surface reflectance, since the incident solar light cannot reach lower altitude and light scattered in the lower atmosphere cannot easily reach the TOA (because of strong $\mathrm{O}_{2}$ absorption). In other words, $\mathrm{O}_{2}$ layer in the lower part of atmosphere now acts as a black surface.

The third region is located between the above defined first and second regions. In this region, light can penetrate through and be reflected by the lower atmosphere (and surface depending on absorption optical depth), and thus intensity and polarization of the upwelling radiation at TOA have the sensitivity to the vertical distribution of scattering in the whole atmospheric column when surface is not black. However, for black surfaces (with $A_{\mathrm{s}}=0$ ), Rayleigh scattering becomes the only source for DOLP and, hence, DOLP is also largest (up to $57 \%$ ). 

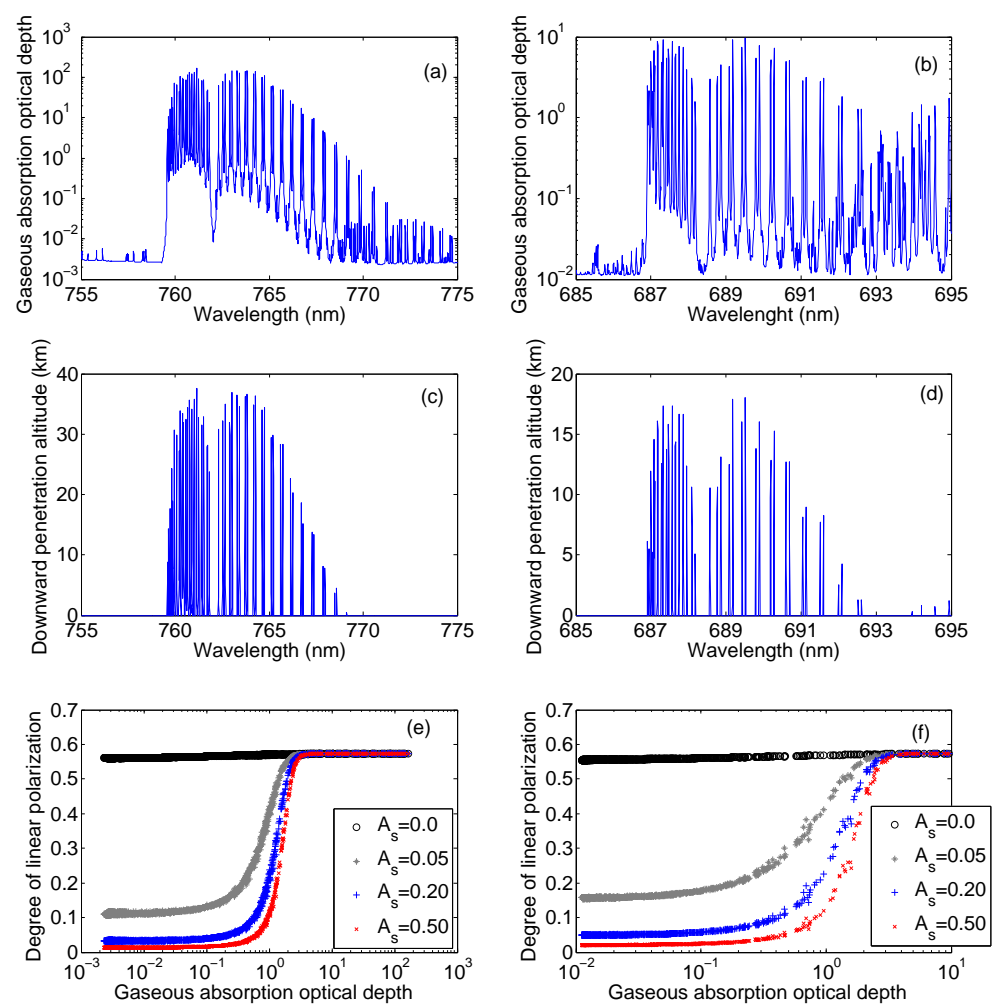

Figure 1. (a) Spectral absorption optical depth of atmosphere in the $\mathrm{O}_{2} \mathrm{~A}$ band. (b) Same as in (a) but in $\mathrm{O}_{2} \mathrm{~B}$ band. (c) Penetration altitude for various wavelengths in the $\mathrm{O}_{2} \mathrm{~A}$ band. (d) Same as (c) but for the $\mathrm{O}_{2} \mathrm{~B}$ band. The spectral interval and resolution (full-width at half maximum of a Gaussian spectral response) of $0.01 \mathrm{~nm}$ is used for the mid-latitude summer atmospheric profile. (e) Degree of linear polarization as a function of gas absorption depth in the $\mathrm{O}_{2} \mathrm{~A}$ band. (f) Same as in (e) but for the $\mathrm{O}_{2} \mathrm{~B}$ band. The penetration altitude is defined as the altitude at which the intensity of the downward radiance (for solar zenith angle of $0^{\circ}$ ) is decreased by a factor of $e$ as compared to its value at the top of the atmosphere. In atmospheric window channels the penetration altitude is set to 0 (i.e., at the surface). Note, the $y$ axis scales are different between panel (a) and (b), and panel (c) and (d). This difference is due to the large $\mathrm{O}_{2}$ optical depth in the $\mathrm{O}_{2} \mathrm{~A}$ band than in the B band.

In summary, when surface is black and/or $\mathrm{O}_{2}$ absorption in the lower part of the atmosphere is large enough to completely prevent the light reaching the surface, the backscattered DOLP is from the Rayleigh scattering only and is always close to $57 \%$. For black surface only, there is a slight $(\sim 1 \%)$ increase of DOLP as $\mathrm{O}_{2}$ optical depth increases (from nearly 0 to 10). This small increase of DOLP is due to a slight decrease of effective Rayleigh optical depth that interacts with the light; the slight decrease is because path length of light is getting shorter with the increase of $\mathrm{O}_{2}$ absorption. As atmospheric aerosols can affect scattering optical depth at various altitudes, it is expected that aerosols can change DOLP in $\mathrm{O}_{2} \mathrm{~A}$ and $\mathrm{B}$ bands, and the spectral variation of DOLP within these bands should have information on vertical distribution of aerosol scattering.

\subsection{Sensitivity of DOLP to the aerosol vertical distribution}

To investigate the sensitivity of DOLP and intensity to aerosol vertical distribution, we focus mainly on two param- eters, the aerosol peak height $(H)$ and half width $(\gamma)$ at half maximum, which are essential to determine the aerosol vertical profile as mentioned in the previous section.

To explain the physics underlying the results, we first present the results for four different aerosol profile examples (Fig. 2a) in which the aerosol peak height $H$ varies from 4 to $13 \mathrm{~km}$ with an increment of $3 \mathrm{~km}$. Here, the column aerosol optical depth is assumed to be 0.2 and $\gamma$ is $1 \mathrm{~km}$. Figure $2 \mathrm{~b}$ shows the differences of DOLP $(\triangle D O L P)$ from one wavelength $\left(759.98 \mathrm{~nm}\right.$ ) within the $\mathrm{O}_{2} \mathrm{~A}$ band to the nearby continuum band $(757 \mathrm{~nm})$ for surface reflectances of $0.0,0.05$, 0.2 and 0.5 . The solar zenith angle and view zenith angle are 66 and $0^{\circ}$, respectively. It can be seen that $\triangle \mathrm{DOLP}$ increases as the surface reflectance increases, which is caused by relatively larger increase of multiple scattering between the surface and atmosphere in the continuum band (than in the $\mathrm{O}_{2}$ absorption band).

The $\triangle$ DOLP values for $A_{\mathrm{s}}$ of 0.2 and 0.5 show much smaller differences (within 0.05 in Fig. 2b), suggesting the advantage of using DOLP to characterize aerosol properties 

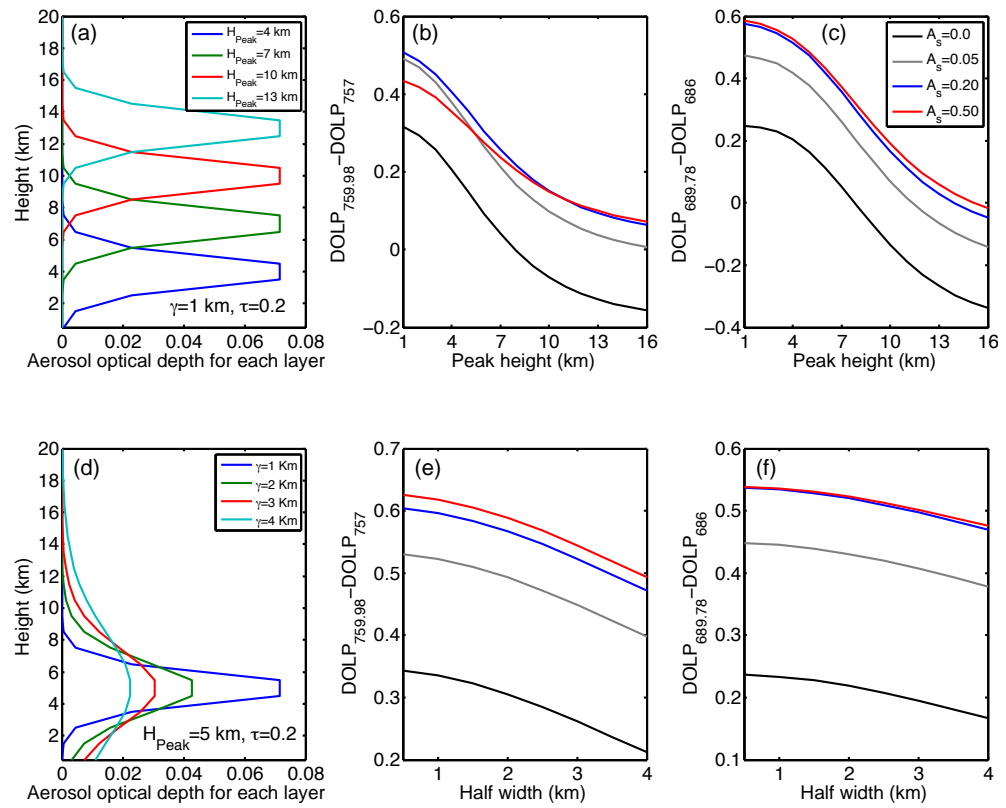

Figure 2. (a) The profile of aerosol optical depth for each layer. (b) Difference of DOLP between 759.98 (absorption channel in $\mathrm{O}_{2} \mathrm{~A}$ band) and $757 \mathrm{~nm}$ (continuum channel) as a function the aerosol peak height for different surface albedos. (c) Same as (b) but for $689.78 \mathrm{~mm}$ (inside $\mathrm{O}_{2} \mathrm{~B}$ band) and $686 \mathrm{~nm}$ (outside $\mathrm{O}_{2} \mathrm{~A}$ band). (d) The profile of aerosol optical depth for different half width. (e-f) Same as (b-c) but as a function of half width at different absorption wavelengths. The solar zenith angle and view zenith angle are 66 and $0.0^{\circ}$, respectively.

over the bright surfaces. Indeed, the variation of $\triangle \mathrm{DOLP}$ with peak height appears similar regardless of the surface reflectance. For a given surface reflectance, $\triangle D O L P$ decreases as the aerosol peak height increases (Fig. 2b). While the DOLP of Rayleigh scattering is positive and strong, the DOLP of spherical aerosols is negative and weaker compared to that of Rayleigh scattering. Consequently, the increase of scattering by aerosols, as aerosol gets aloft, can partially offset the effects of Rayleigh scattering, resulting in less positive DOLP in $\mathrm{O}_{2} \mathrm{~A}$ band (Wang et al., 2014). In the continuum band, however, Zeng et al. (2008) showed that DOLP is not sensitive to the aerosol height as the scattering is primarily due to aerosol optical depth. It is noted that the lower the aerosol layer, the increased absorption in $\mathrm{O}_{2} \mathrm{~A}$ band suppresses the aerosol scattering. This explains the increase of DOLP (and $\triangle$ DOLP) in the $\mathrm{O}_{2} \mathrm{~A}$ band as the aerosol peak height decreases (closer to the surface). The same patterns can be seen in the $\mathrm{O}_{2} \mathrm{~B}$ band (Fig. 2c). The change of DOLP with respect to the aerosol peak height also has wavelength dependence. Indeed, in some absorption wavelengths, the $\mathrm{O}_{2}$ absorption optical depths can be sufficiently large $(\sim 7.7$ at $689.78 \mathrm{~nm}$ ) that aerosols near the surface have much less chance to interact with the incident light. Thus, the DOLP differences at these wavelengths are more sensitive to highaltitude aerosol layers (7-10 km, Fig. 1c). However, at some other wavelengths, the $\mathrm{O}_{2}$ absorption optical depths (such as $\sim 0.88$ at $759.98 \mathrm{~nm}$ ) are relatively smaller and the light can reach lower atmosphere. The DOLP differences at these wavelengths are more sensitive to low-altitude aerosol layers (4-7 km, Fig. 1b).

Figure $2 \mathrm{~d}$ is the profile of aerosol optical depth for different $\gamma$ values, where $H$ is $5 \mathrm{~km}$ and the column aerosol optical depth is assumed to be 0.2 . Similar to Fig. $2 \mathrm{~b}-\mathrm{c}$, e-f show the $\triangle$ DOLP for various $\gamma$ values (with the same $H$ ). Consistent with Fig. $2 \mathrm{~b}$ and c, $\triangle$ DOLP decreases as the surface reflectance increases. Also, it can be seen that for given surface reflectance, as $\gamma$ increases, $\triangle \mathrm{DOLP}$ decreases. Because $\mathrm{O}_{2}$ absorption coefficient above the aerosol peak height is smaller than that below the aerosol peak height, the elevated portion of aerosols above the peak height (due to the increase of profile half width) has a larger effect on DOLP than the counterpart below the aerosol peak height, counteracting more positive DOLP from Rayleigh scattering.

To further evaluate whether the findings revealed in Fig. 2 can be generalized, we compute the DOLP at $759.98 \mathrm{~nm}$ at TOA as a function of $H$ and $\gamma$ for $A_{\mathrm{s}}$ of $0,0.2$ and 0.5 , respectively, representing black, bright and highly bright surfaces (Fig. 3). Top panels of Fig. 3 show the results at the scattering angle $\Theta=120^{\circ}$ (a nadir view with solar zenith angle of $60^{\circ}$ ). Bottom panels correspond to scattering angle $\Theta=150^{\circ}$. These results (and their contrasts with their counterparts in continuum band; Fig. S1 in the Supplement) confirm that (a) an increase of surface albedo leads to more depolarization (e.g., decrease the positive DOLP for $\Theta=120^{\circ}$ and make less negative DOLP for $\Theta=150^{\circ}$ ) at TOA, and (b) DOLP in $\mathrm{O}_{2} \mathrm{~A}$ band decreases as the peak height $H$ increases for the same $\gamma$ value. Moreover, these results also 
suggest that DOLP in $\mathrm{O}_{2} \mathrm{~A}$ band at TOA has a strong angular dependence. It can be seen that the DOLP at $\Theta=120^{\circ}$ is positive for all chosen $H$ and $\gamma$. The maximum of DOLP at TOA occurs when aerosols appear in the near surface. In contrast, DOLP at $\Theta=150^{\circ}$ is found to be negative for all combinations of aerosol peak height and half width (bottom three panels in Fig. 3). This contrast can be explained by the different angular dependence of DOLP between Rayleigh scattering and aerosol scattering. As discussed in Wang et al. (2014), the DOLP of Rayleigh scattering (Fig. 8 in Wang et al., 2014) is positive at all scattering angles (with peak value at $\Theta=90^{\circ}$ and 0 at $\Theta=180^{\circ}$ ); aerosol particles often yield negative DOLP at all backscattering angles, with the largest negative DOLP at around $\Theta=150^{\circ}$. Regardless of angle, however, it is expected that the increase of aloft aerosol scattering, either through increase of peak height or through increase of half width or both, can lead to a decrease of DOLP for the same surface reflectance (Fig. 3).

\subsection{Calculation of the DFSs}

The actual observations inevitably contain instrumental error and measurement noise. It is critical to properly treat these experimental errors in the design of retrieval methods. In the following analysis we assume that aerosol properties including optical depth are known with some uncertainties, and the parameters to be retrieved are related to aerosol vertical profile only. Hence, the measurement errors defined here also include the model errors.

To compare the information content of the DOLP and intensity at TOA for retrieving aerosol vertical distribution, we calculate the DFSs for aerosol peak height $H$ at each individual wavelength (or channel at $0.01 \mathrm{~nm}$ spectral resolution across $\mathrm{O}_{2} \mathrm{~A}$ and $\mathrm{B}$ bands) using (a) only radiances in $\mathrm{O}_{2} \mathrm{~A}$ band, (b) only DOLP in $\mathrm{O}_{2}$ A band and (c) only DOLP in the $\mathrm{O}_{2} \mathrm{~B}$ band. It can be seen in Fig. 4a that the maximum DFS for using radiance is only about 0.35 at the wavelength near $759.7 \mathrm{~nm}$ in the $\mathrm{O}_{2}$ A band. However, the DFSs for using DOLP are often larger than 0.4, with maxima values close to unity, in both $\mathrm{O}_{2}$ A (Fig. 4b) and $\mathrm{O}_{2}$ B bands (Fig. 4c). Figure 4 hence suggests that the polarization of light contains more information on the aerosol peak height than that of intensity.

The DFS values in Fig. $4 \mathrm{~d}-\mathrm{f}$ are sorted in descending order for three cases in Fig. 4a-c. The $x$ axis in Fig. 4d-f indicates the number of spectral wavelengths (or channels). The leftside $y$ axis indicates DFSs and the right-side $y$ axis represents the corresponding gaseous absorption optical depth for an individual wavelength. As shown in Fig. 4d, the gaseous absorption optical depths corresponding to the first ten maximum DFSs of radiance in the $\mathrm{O}_{2} \mathrm{~A}$ band are above 5.0. In contrast, the counterparts for the DFSs of DOLP in $\mathrm{O}_{2}$ $\mathrm{A}$ and $\mathrm{B}$ bands are above 1.0 and 0.35 , respectively (see Fig. $4 \mathrm{e}$ and $\mathrm{f}$ ). Furthermore, there are no less than 10 wavelengths (simulated at $0.01 \mathrm{~nm}$ interval) with DFS values close
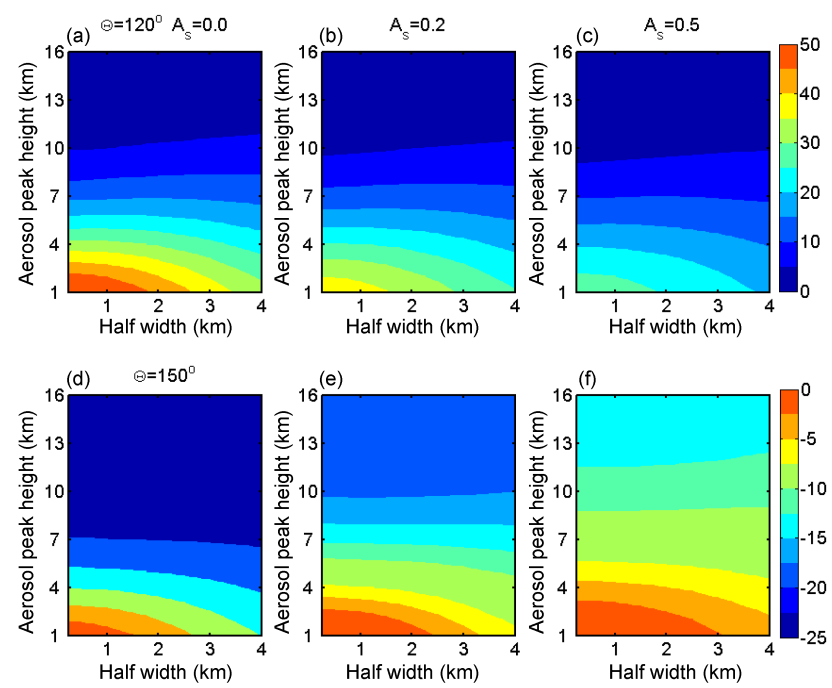

Figure 3. Contours of the DOLP at TOA as functions of aerosol peak height and half width at two different scattering angles, $\Theta=120^{\circ}$ (upper panels) and $\Theta=150^{\circ}$ (lower panels), for three different surface albedo, $0.0,0.2$ and 0.5 . The wavelength is $759.98 \mathrm{~nm}$.
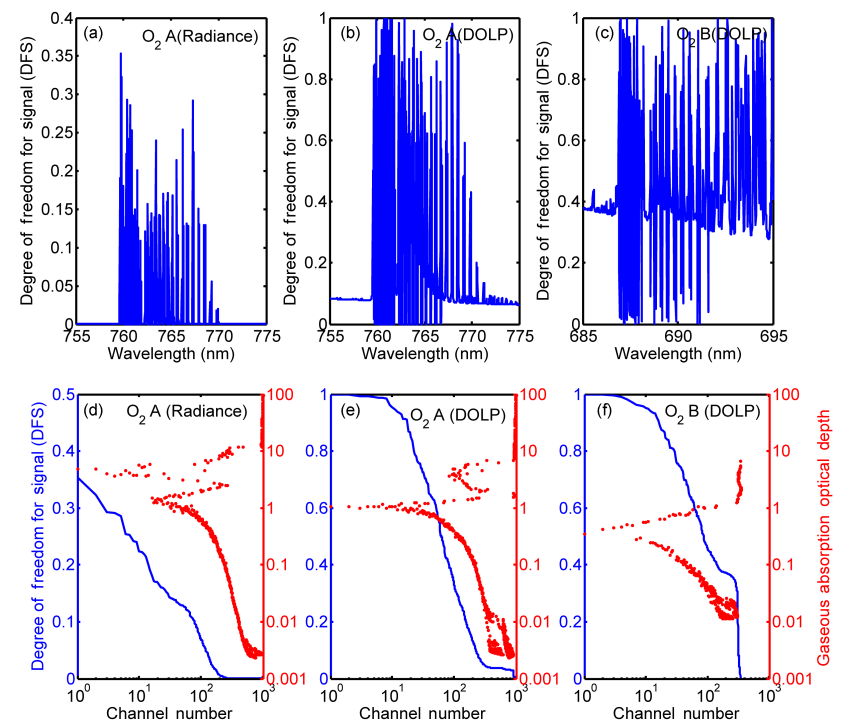

Figure 4. Degree of freedom of signal of individual channel within $\mathrm{O}_{2} \mathrm{~A}$ and $\mathrm{B}$ bands, calculated from (a) radiance in $\mathrm{O}_{2} \mathrm{~A}$ band, (b) DOLP in $\mathrm{O}_{2} \mathrm{~A}$ band and (c) DOLP in $\mathrm{O}_{2} \mathrm{~B}$ band. (d) Sorted degree of freedom of signal (blue) calculated from radiance in $\mathrm{O}_{2}$ A band, and corresponding gas absorption optical depth (red) for both $\mathrm{O}_{2} \mathrm{~A}$ and $\mathrm{B}$ band. (e) and (f) are the same as (d) but calculated from DOLP in $\mathrm{O}_{2} \mathrm{~A}$ and $\mathrm{B}$ bands, respectively.

to 1 in DOLP measurements in both $\mathrm{O}_{2} \mathrm{~A}$ and $\mathrm{B}$ bands, but the DFS values of radiance measurements are always below 0.4. These findings from Fig. 4 further suggest that DOLP can have more information content for inferring aerosol peak height $H$ than intensity. 

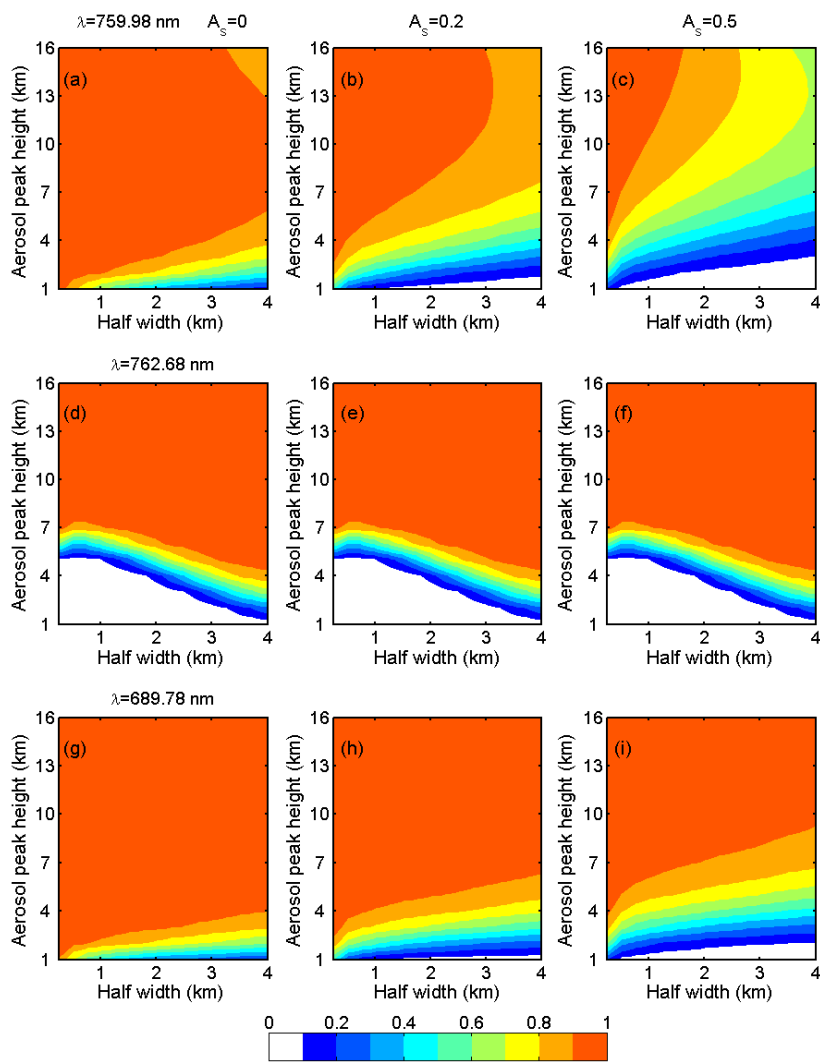

Figure 5. Contours of degree of freedom of signals of DOLP for retrieving aerosol peak height as a function of aerosol peak height $H$ and half width at half maximum $\gamma$ at three difference wavelengths in both $\mathrm{O}_{2} \mathrm{~A}$ and $\mathrm{B}$ bands for different surface albedo, 0.0, 0.2 and 0.5. The gas absorption optical depths at wavelength 759.98, 762.68 and $689.78 \mathrm{~nm}$ are $0.88,2.73$ and 0.34 , respectively.

Figure 5 shows the DFS in DOLP measurements for inferring $H$ as a function of aerosol peak height $H$ and half width at half maximum $\gamma$ for three wavelengths in both $\mathrm{O}_{2}$ bands for different surface reflectance values of 0.0, 0.2 and 0.5. We can find that, at some wavelengths where the $\mathrm{O}_{2}$ absorption optical depths are smaller relatively (such as $759.98 \mathrm{~nm}$ ), the DFS values are more influenced by the change of surface reflectance than at other wavelengths where the $\mathrm{O}_{2}$ absorption optical depths are larger (such as $762.68 \mathrm{~nm}$ with optical depth of 2.7). Indeed, DFS approaches 0 at $762.68 \mathrm{~nm}$ for aerosol peak height less than $2 \mathrm{~km}$. For the same wavelength (e.g., each row in Fig. 5), DFS values decrease as the surface reflectance increases; for surface reflectance of 0.5 , the DFS is less than 0.5 for aerosol peak height $H$ below $2 \mathrm{~km}$, regardless of $\gamma$.

Similarly, we calculate the DFS in DOLP measurements for $\gamma$ (Fig. 6). It can be seen that although the DFS values are not as sensitive to the change of surface reflectance as that shown in Fig. 5 for inferring aerosol peak height, they have remarkable spectral dependence. At some wavelengths such as 759.98 and $689.78 \mathrm{~nm}$, the DFS values for $\gamma$ are larger
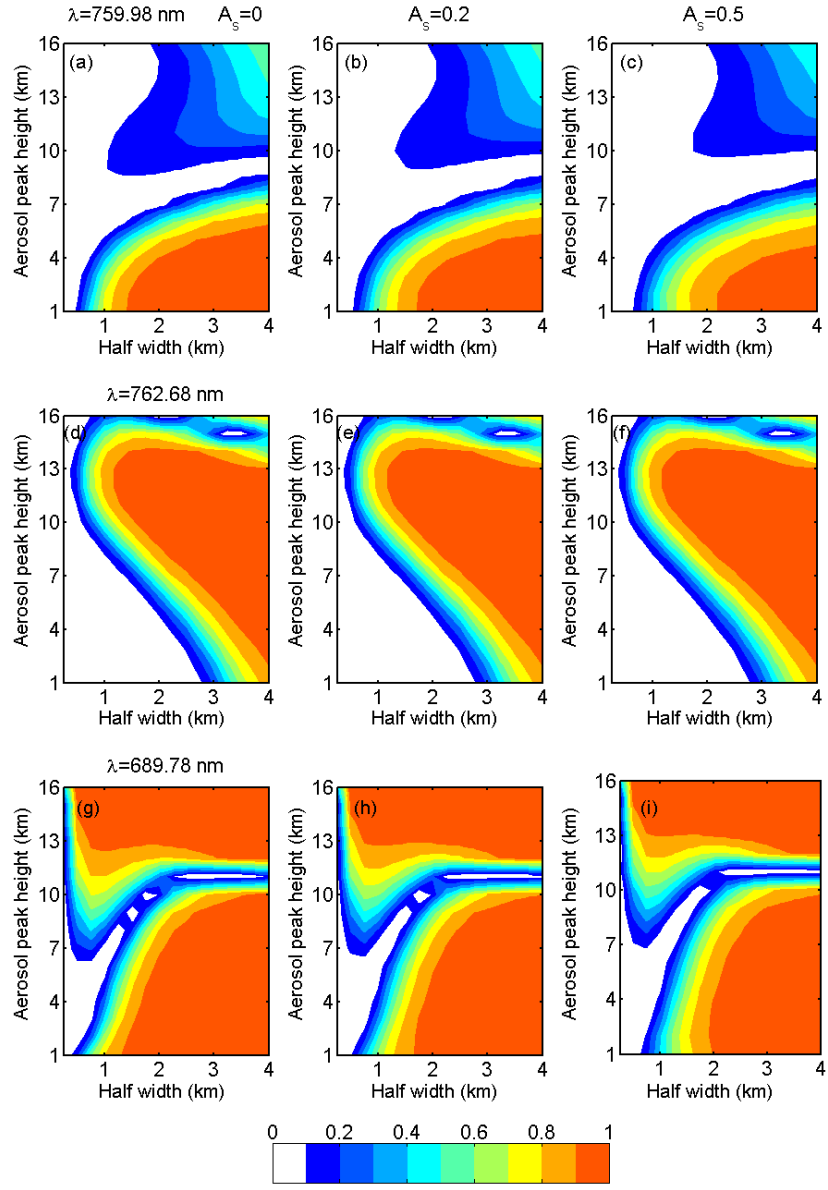

Figure 6. Same as Fig. 5 but for the DFSs for retrieving profile half width.

(than 0.5) for low-level aerosol layer $H$ below $2 \mathrm{~km}$ except for $\gamma$ less than $1 \mathrm{~km}$; however, at other wavelengths such as $762.68 \mathrm{~nm}$, the DFS values for $\gamma$ are more sensitive to higher aerosol layer. While results in Figs. 5 and 6 are calculated for measurement error of $5 \%$, a smaller measurement error yields larger DFS values for $H$ and $\gamma$ (Figs. S2 and S3) and measurement error of $8 \%$ gives results similar to those from $5 \%$ (with DFS difference often less than 0.05).

The following question arises: can the two pieces of information for aerosol vertical profile (e.g., peak height and half width) be retrieved from combined use of several different wavelengths in both $\mathrm{O}_{2} \mathrm{~A}$ and $\mathrm{B}$ bands? To address this question, we select the most informative channels following Rodgers (1996). We first sorted DFS values in DOLP measurements at each wavelength (or channel at $0.01 \mathrm{~nm}$ resolution) in a descending order in both $\mathrm{O}_{2} \mathrm{~A}$ and $\mathrm{B}$ bands for a baseline aerosol vertical distribution with peak height $H$ of $8 \mathrm{~km}$ (the middle value in $0-16 \mathrm{~km}$ range of peak height values we analyzed), half width at half maximum of $1 \mathrm{~km}$ and surface reflectance of 0.2 . The first channel is selected with the maximum DFS for $H$. Subsequently, DFSs are examined 

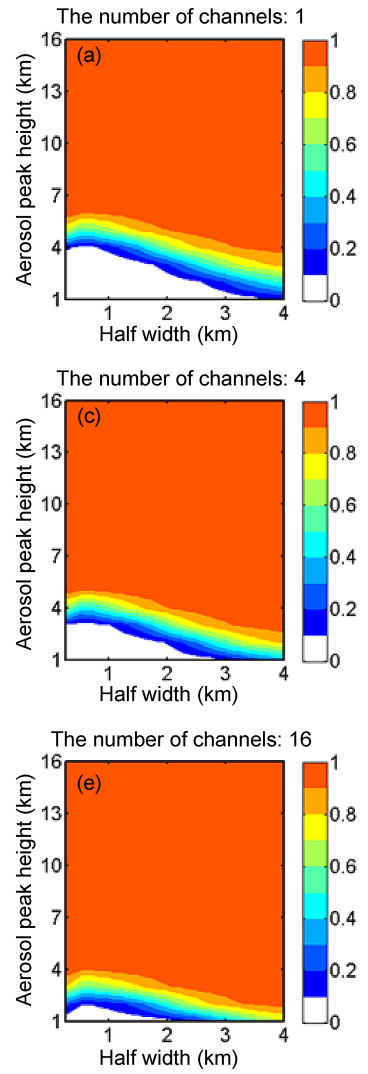

Figure 7. DFSs of DOLP for retrieving aerosol peak height calculated from various number $(1,2,4,8,16$ and 32) of selected channels in $\mathrm{O}_{2} \mathrm{~A}$ band as a function of aerosol peak height and half width. The surface reflectance is assumed to be 0.2 .

for a combination of the first channel to any of the rest channels, and the second channel is identified when the largest DFS value is achieved. More channels are further selected with the same process applied and thereby, each additional channel leads to the increase of DFS values at the possibly largest increasing rate. Once the sequence and the group of these channels are defined for the baseline case, these channels are used to evaluate DFS for all other cases with different combinations of $H$ and $\gamma$.

Figure 7a shows the DFSs of the first channel DOLP in the $\mathrm{O}_{2} \mathrm{~A}$ band for the retrieval of aerosol peak height $H$ (e.g., $764.76 \mathrm{~nm}$, the channel that maximizes DFS for the baseline vertical profile) as a function of various combinations of $H$ and $\gamma$ values. It reveals that aerosol peak height $H$ can be easily retrieved by using the first channel (regardless of $\gamma$ values), given that other aerosol parameters are well characterized, for those aerosol layers higher than $5.5 \mathrm{~km}$. However, DFS decreases rapidly and is nearly 0 when most aerosols start to concentrate near the surface (e.g., as $H$ and $\gamma$ values approach from $4 \mathrm{~km}$ to 0 or approach the bottom corner of the panel in Fig. 7a). As expected, DFS value for $H$ increases as more channels are used $(2,4,8,16$ and 32 shown
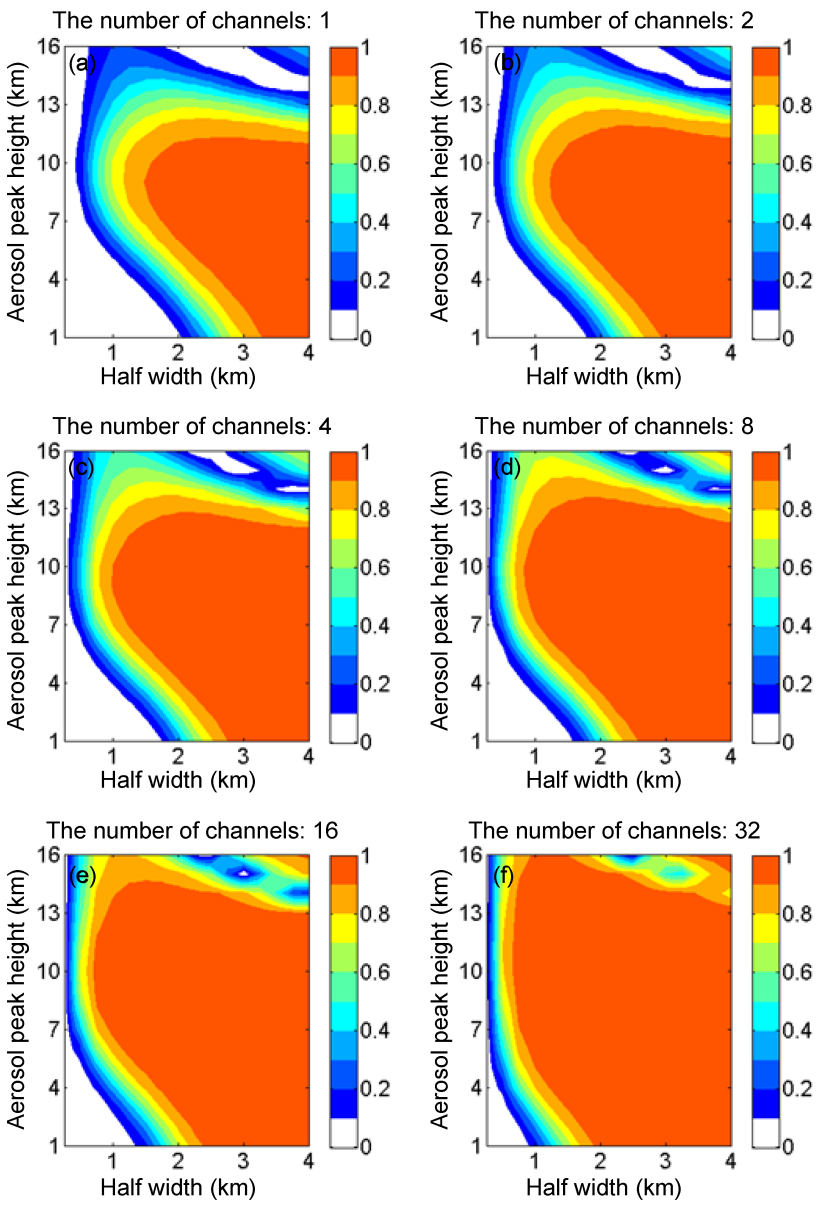

Figure 8. Same as Fig. 7 but for DFSs for retrieving profile half width.

in Fig. 7b-f), especially when the aerosol layer is close the surface. For example, the white zone with 0 DFS in the bottom left corner in Fig. 7a is slowly filled up with colors of DFS $>0.1$ from Fig. $7 b-f$. Even with 32 channels, however, DFS is still smaller than 0.4 when $H$ is smaller than $2 \mathrm{~km}$ (Fig. 7f). Therefore, a greater number of channels or better DOLP accuracy and measurement accuracy (uncertainty less than $5 \%$ ) are required to gain a sufficient signal for retrieving aerosol distribution below the boundary layer. It is noted, however, that current measurements of DOLP often have an uncertainty less than $1 \%$ (and sometimes around $0.2 \%$ ) and measurements of intensity have an uncertainty of $2 \%$ (Zeng et al., 2008). Therefore, there is still potential in using DOLP in $\mathrm{O} 2 \mathrm{~A}$ and $\mathrm{B}$ bands to characterize aerosol distribution even within $2 \mathrm{~km}$ above the surface.

Similar to Fig. 7, we calculated the DFS values for $\gamma$ for a different number of channels in $\mathrm{O}_{2} \mathrm{~A}$ and $\mathrm{B}$ bands and the results are presented in Fig. 8. The pattern of DFS in Fig. 8 is different from that in Fig. 7; Fig. 8 has the maxima of DFS in the bottom right corner of each panel while the latter has the maxima of DFS on the top. In other words, 

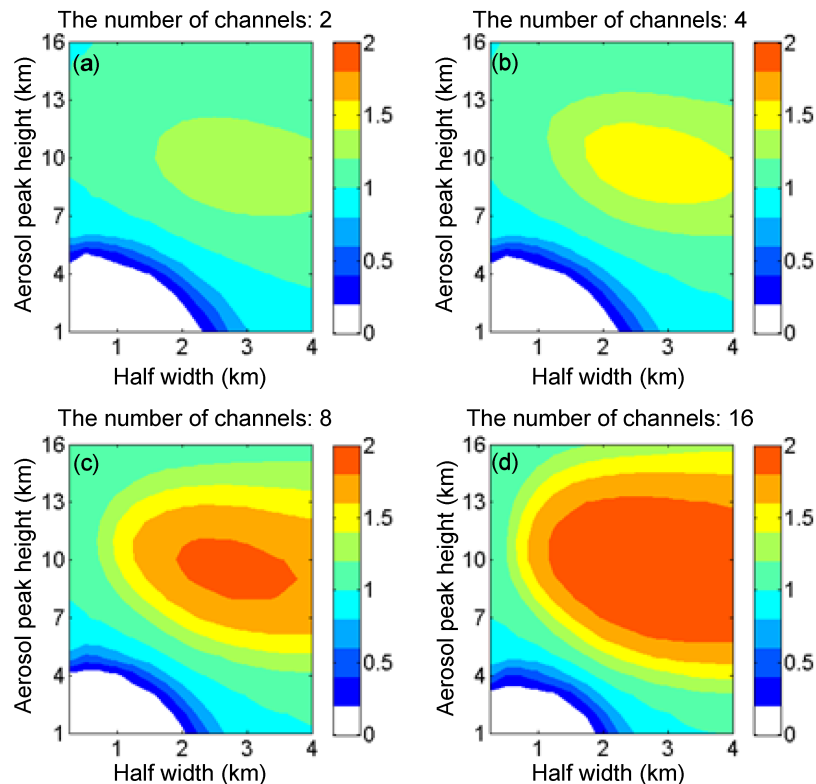

The number of channels: 32
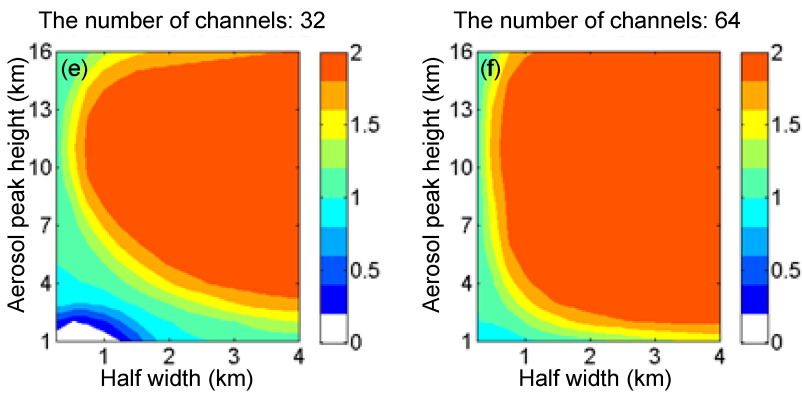

Figure 9. Contours of degree of freedom of signals of DOLP for simultaneously retrieving aerosol profile $H$ and half width at half maximum $\gamma$ calculated from various number $(2,4,8,16,32$ and 64) of pre-selected channels in $\mathrm{O}_{2} \mathrm{~A}$ band as a function of aerosol peak height and half width. The surface albedo is assumed to be 0.2 . The pre-selected channels are a result of optimization for the case with $H$ of $8 \mathrm{~km}$ and $\gamma$ of $1 \mathrm{~km}$.

for larger $H$, DOLP has less sensitivity to large $\gamma$. Regardless, the physics remains the same: DFS increases when there are more aerosols in the upper layer (e.g., either lager $H$ or larger $\gamma$ width or both). It is interesting to note that DFS seems to increase with altitude up to about $10-12 \mathrm{~km}$ but decreases very quickly above that because the $\mathrm{O}_{2}$ absorption is much weaker there. As shown in Fig. 8, we find that using 32 channels can retrieve $\gamma$ well for most possible vertical distributions of aerosols, except when aerosols present within a low-altitude thin layer or highly aloft.

After we calculated the DFS values for a single parameter of aerosol vertical distribution (either $H$ or $\gamma$, respectively) for various number of selected channels, we calculated the DFS values in DOLP measurements from various selected channels in the $\mathrm{O}_{2}$ A band for retrieving $H$ and $\gamma$ simultaneously. Hence, the maximum DFS value in this kind of analysis is 2. Figure 9 shows these DFS values as a func-
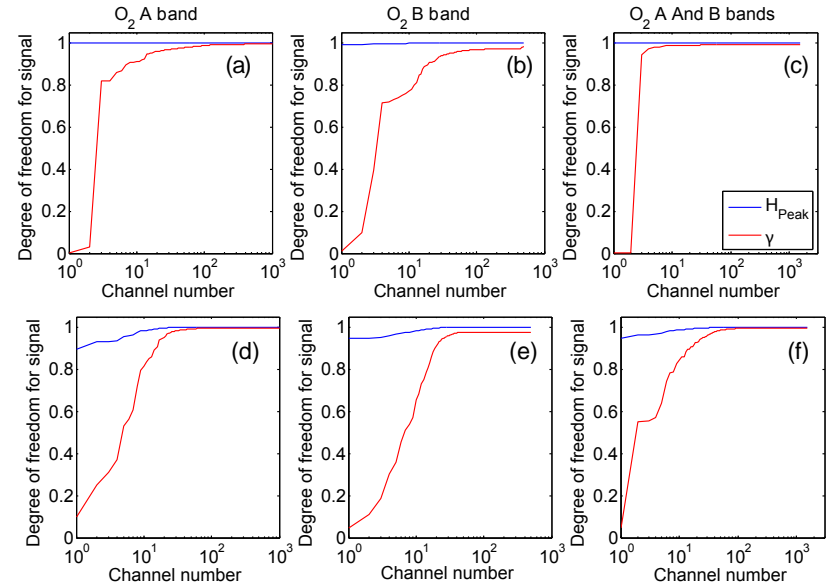

Figure 10. Degree of freedom of signal of DOLP for retrieving both aerosol peak height $H$ and half width at half maximum $\gamma$ as a function of the number selected channels from $\mathrm{O}_{2} \mathrm{~A}$ band only (left column), $\mathrm{O}_{2} \mathrm{~B}$ band only (middle column) and from $\mathrm{O}_{2} \mathrm{~A}$ and $\mathrm{B}$ bands together (right column). The top row is for the cases with $H$ of $8 \mathrm{~km}$ and $\gamma$ of $1 \mathrm{~km}$, while the bottom row is for $H$ of $5 \mathrm{~km}$ and $\gamma$ of $1 \mathrm{~km}$. See the text for details.

tion of $H$ and $\gamma$. As we can see from Fig. 9, the retrievable regions are very limited when only a few number of channels $(<8)$ are used. However, with more channels used, DFS values can approach 2 when aerosol peaks in the middle troposphere with large $\gamma$ values. As shown in Fig. 9f, when 64 wavelengths are used to retrieve $H$ and $\gamma$ values simultaneously, the retrievable regions cover most possible vertical distributions of aerosols, except for aerosols near the surface or aerosols within a very thin layer (e.g., $\gamma$ less than $1 \mathrm{~km}$ ).

Figure 10a-c show the DFS values for simultaneously retrieving $H$ and $\gamma$ with the DOLP in (a) $\mathrm{O}_{2}$ A band, (b) $\mathrm{O}_{2} \mathrm{~B}$ band and (c) the combination of $\mathrm{A}$ and $\mathrm{B}$ bands. It is evident that the combined use of $\mathrm{O}_{2} \mathrm{~A}$ and $\mathrm{B}$ bands (Fig. 10c) can significantly enhance the information content compared to the use of only the A (Fig. 10a) or B band (Fig. 10b) and can decrease the number of required channels for a sufficiently accurate retrieval. Figure 10c shows that 10 channels from $\mathrm{O}_{2}$ A and B bands, as listed in Table 2, are sufficient to resolve $H$ and $\gamma$ for the cases studied (where $H$ and $\gamma$ are assumed to be 5.0 and $1.0 \mathrm{~km}$, respectively).

The wavelength that is used to define the baseline case and therefore the sequence of channels does have effects on the final results, but the overall conclusion remains the same. Results similar to Figs. $10 \mathrm{a}-\mathrm{c}$ and 9 but using $H$ of $5 \mathrm{~km}$ instead of $8 \mathrm{~km}$ to select the channels as the baseline case are presented in Figs. 10d-e and 11, respectively. The smaller the $H$, the larger number of channels is needed to make DFS values for $H$ and $\gamma$ both reach unity (e.g., as seen from the contrast between Fig. 10a-c and d-f). However, as expected, for the group of channels that are optimally selected for smaller $H$ (such as $5 \mathrm{~km}$ ), they also have more information charac- 

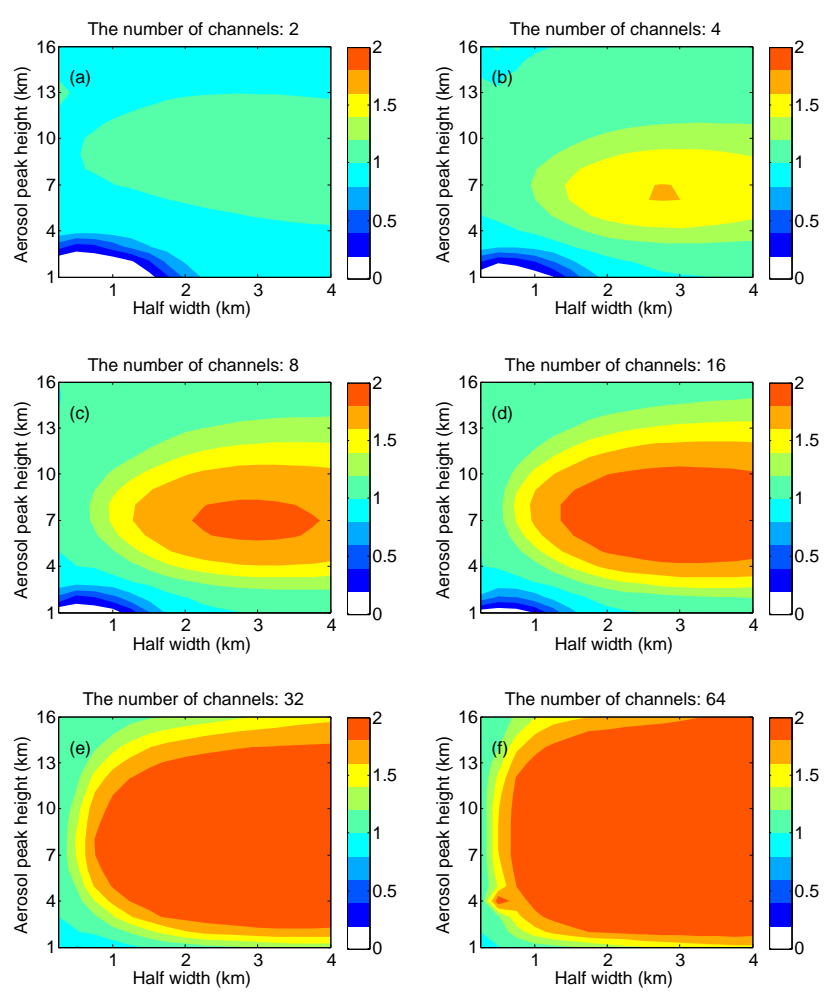

Figure 11. Same as Fig. 9 except that the pre-selected channels are a result of optimization for $H$ of $5 \mathrm{~km}$ and $\gamma$ of $1 \mathrm{~km}$.

terizing $H$ for cases where $H$ is also lower (e.g., $3 \mathrm{~km}$ ). For example, only 16 channels are needed in Fig. 11 (in which baseline case has $H$ of $5 \mathrm{~km}$ ) to make total DFS for $H$ and $\gamma$ up to 1 for the case with $H$ of $2.5 \mathrm{~km}$ and $\gamma$ of $1.8 \mathrm{~km}$; in contrast, in Fig. 9 (in which baseline case has $H$ of $8 \mathrm{~km}$ ), the first 16 channels yield less than 0.2 DFS values for the same case with $H$ of $2.5 \mathrm{~km}$ and $\gamma$ of $1.8 \mathrm{~km}$. For the completeness, we also show the first 10 channels that are optimal for characterizing $H$ of $5 \mathrm{~km}$ and $\gamma$ of $1 \mathrm{~km}$ in Table S1 in the Supplement. Also shown in Fig. S4 are results similar to those in Fig. 9, but using the channels for the baseline case with $H$ of $1 \mathrm{~km}$ and $\gamma$ of $1 \mathrm{~km}$. Overall, from all the cases we examined, we found that DOLP in $\mathrm{O}_{2} \mathrm{~A}$ and $\mathrm{B}$ bands have rich and fine-structure information for retrieving a wide range of $H$ and $\gamma$ values. Such fine-structure information can only be obtained with measurements of DOLP taken at hyperspectral resolution. DFS needed for simultaneous retrieval of $H$ and $\gamma$ for high-lofted, or near-surface (with $H$ of $1 \mathrm{~km}$, for example, in Fig. S4), aerosol profiles can be obtained from a combined use of DOLP measurements at $\sim 10-100 \mathrm{O}_{2} \mathrm{~A}$ and $\mathrm{B}$ absorption wavelengths, depending on the specific values of $H$. Future studies are needed to reveal how the spectral resolution of DOLP measurements may affect the retrieval accuracy of $H$ and $\gamma$.

The results presented above are based on the calculations that assume spherical dust particles. As a compari-
Table 2. The first ten wavelengths selected for maximum contribution to the total information content from $\mathrm{O}_{2} \mathrm{~A}$ and $\mathrm{B}$ bands for the case with $H$ of $8 \mathrm{~km}$ and $\gamma$ of $1 \mathrm{~km}$.

\begin{tabular}{lrcc}
\hline No. & $\begin{array}{r}\text { Wavelength } \\
(\mathrm{nm})\end{array}$ & \multicolumn{2}{c}{ DFS* } \\
& & $\gamma$ \\
\hline 1 & 762.68 & 0.9998 & 0.0002 \\
2 & 761.04 & 0.9998 & 0.0035 \\
3 & 687.84 & 1.0000 & 0.9453 \\
4 & 692.60 & 1.0000 & 0.9720 \\
5 & 687.34 & 1.0000 & 0.9805 \\
6 & 760.82 & 1.0000 & 0.9806 \\
7 & 692.08 & 1.0000 & 0.9841 \\
8 & 694.94 & 1.0000 & 0.9866 \\
9 & 760.96 & 1.0000 & 0.9866 \\
10 & 686.98 & 1.0000 & 0.9882 \\
\hline
\end{tabular}

* DFS values for both peak height and half width corresponding to the channel number $n$ are the result of information content analysis from a combined use of the first channel to channel number $n$.

son, we also investigate other types of aerosols listed in Table 1, including soot (absorbing) and sulfate (non-absorbing) aerosols. Figure 12 shows the comparison of the DOLP at TOA and their corresponding DFS values for three types of aerosols, dust, sulfate and soot, as functions of aerosol peak height and half width at the scattering angle $120^{\circ}$. The wavelength is $759.98 \mathrm{~nm}$. The figure shows that highly absorbing aerosols (such as soot; Fig. 12c) can lead to a smaller decrease of DOLP (or larger DOLP) as compared to the counterparts by less absorbing (such as dust; Fig. 12a) and pure scattering aerosols (such as sulfate; Fig. 12b); this can be understood because absorbing aerosols suppress the multiple scattering at the atmosphere. Correspondingly, the information content in DOLP (in terms of DFS values) is generally smaller for characterizing vertical profile of absorbing aerosols (as shown by the contrast between Fig. 12f and d$\mathrm{e}$ and the contrast between Fig. 12i and g-h). However, while these difference of DFS exist between various type of aerosols because of their different physical and optical properties, the patterns of DFS variations generally appear the same regardless of aerosol type, revealing that DFS is higher when aerosols are concentrated at high levels due to larger $H$, larger $\gamma$ or both. Therefore, a combination of DOLP measurements in $\mathrm{O}_{2} \mathrm{~A}$ and $\mathrm{B}$ bands enables the retrieval of aerosol vertical distribution for a wide-range of aerosol types. The results between dust and sulfate particles remain similar, except that DFS values for both $H$ and $\gamma$ are slightly reduced for $H<4 \mathrm{~km}$ and $\gamma>1 \mathrm{~km}$ (e.g., from the contrast between Fig. 12d and e and between Fig. 12g and h). However, for soot particles, the DFS values for $H$ are largely reduced except for high-elevated cases with smaller $\gamma$ (Fig. 12f). These results suggest that the information content in DOLP in $\mathrm{O}_{2}$ $\mathrm{A}$ and $\mathrm{B}$ band decreases with aerosol absorption. Hence, a combination of using both UV radiance and DOLP in $\mathrm{O}_{2}$ ab- 

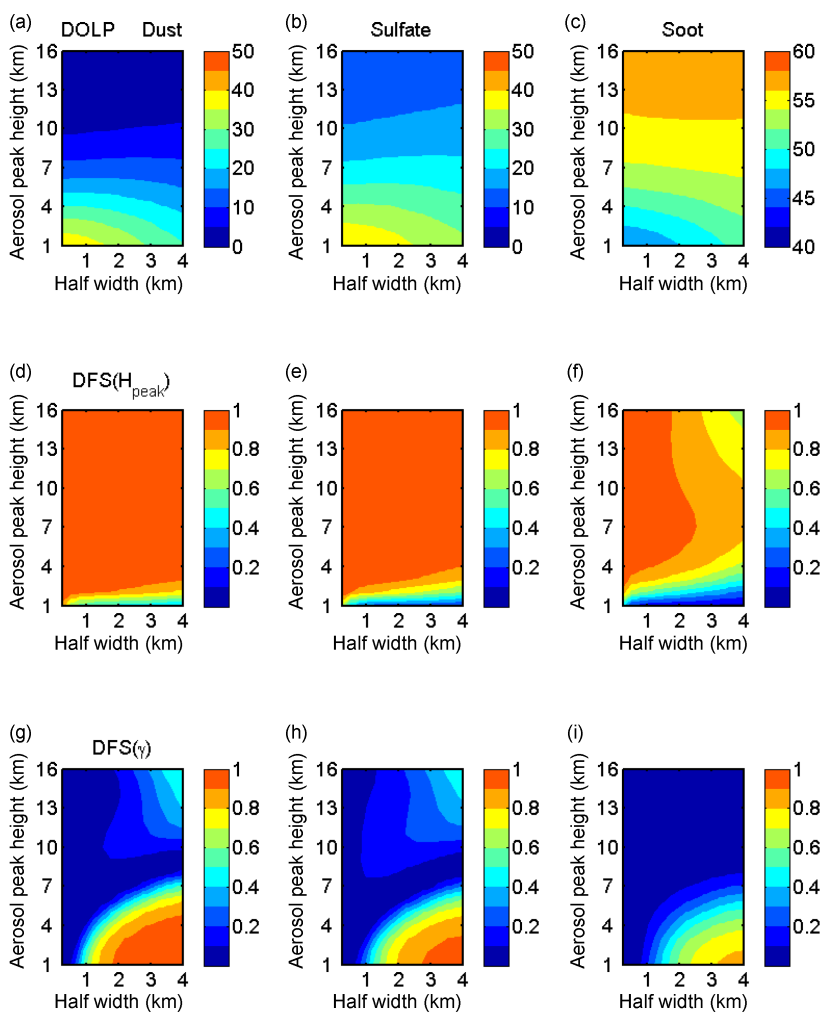

Figure 12. Contours of the DOLP at TOA and DFSs for three types of aerosols, dust, sulfate and soot, as functions of aerosol peak height and half width at the scattering angle $120^{\circ}$. The wavelength is $759.98 \mathrm{~nm}$.

sorption band may enhance the information content for characterizing profiles of absorbing aerosols.

\section{Summary}

In the present study, we carry out radiative transfer simulation in the $\mathrm{O}_{2} \mathrm{~A}$ and $\mathrm{B}$ bands and explain the physics underlying the results. In order to identify the most sensitive spectral channels to the peak height and half width at the half maximum of aerosol vertical distribution, the DFS is used to examine the information contained in each individual wavelength in both $\mathrm{O}_{2}$ absorption bands. Our results show that the DOLP can have more information content for retrieving aerosols vertical distribution than intensity. The analysis suggests that the DOLP at different wavelengths has different sensitivities to the aerosols at different altitudes. Our results also show that the combined use of DOLP in both the $\mathrm{O}_{2} \mathrm{~A}$ and $\mathrm{B}$ bands can significantly enhance the information content and decrease the number of wavelengths needed for simultaneously retrieving aerosol peak height and vertical distribution as opposed to using either $\mathrm{O}_{2} \mathrm{~A}$ or $\mathrm{B}$ band alone.

While a combined use of DOLP in $\mathrm{O}_{2} \mathrm{~A}$ and $\mathrm{B}$ bands is shown to have great potential for characterizing the aerosol vertical profile from a passive remote sensing point of view, it is also shown that the information content is relatively smaller for fully resolving the aerosol vertical distribution (below 1-2 km) near the surface (with 64 spectral channels for measuring DOLP). Regardless, since aerosols ( $0.5-1 \mathrm{~km})$ near the surface are normally well mixed as a result of planetary boundary layer process, using DOLP in $\mathrm{O}_{2} \mathrm{~A}$ and $\mathrm{B}$ bands to further detect and characterize the conditions where significant aerosol amount (including scattering aerosols) occur above the boundary layer over the land (including bright surfaces) can provide valuable supplements to the existing satellite observations for advancing our knowledge of aerosol 3-D distribution in the atmosphere.

For future studies, real measurements of DOLP in $\mathrm{O}_{2} \mathrm{~A}$ and $\mathrm{B}$ bands are needed to further evaluate their potential as well as their combination with DOLP in atmospheric window channels (such as proposed to the PACE) for retrieving aerosol profiles over land. Meanwhile, an existing satellite sensor, EPIC, measures backscattered radiance in both $\mathrm{O}_{2} \mathrm{~A}$ and $\mathrm{B}$ band as well as in the atmospheric window channels in UV spectrum from the Lagrangian point $1(\mathrm{~L} 1,1500000 \mathrm{~km}$ from Earth). A combined use of all these measurements may augment existing (OMI-based) UV-only techniques for retrieving aerosol height information. With PACE and EPICtype sensors in the coming decade, it is foreseeable that passive remote sensing of aerosol height can be conducted on the global and daily basis. Challenges, however, do exist, especially when a sensor's instantaneous field of view is large ( $\sim 20 \mathrm{~km}$ for EPIC and OMI) and is often contaminated by clouds. Since clouds often have much larger optical depth and particle size than aerosols, it is also necessary to study how cloud contamination may affect the results presented here and whether or not DOLP in $\mathrm{O}_{2} \mathrm{~A}$ and $\mathrm{B}$ band can add valuable information for cloud detection and for the existing cloud top height retrieval technique that uses the intensity in $\mathrm{O}_{2}$ A band (Fisher et al., 1991).

\section{The Supplement related to this article is available online at doi:10.5194/amt-9-2077-2016-supplement.}

Acknowledgements. Funding for this study was provided by the NASA Earth Science Division as part of GEO-CAPE mission study and DSCOVR science team research. J. Wang is grateful to Jassim (Jay) A. Al-Saadi for his support and thanks the GEO-CAPE aerosol working group and science working group for their constructive suggestions and fruitful discussions. The Holland Computing Center of University of Nebraska - Lincoln and NASA High-End Computing program are acknowledged for their help in computing.

Edited by: A. Kokhanovsky 


\section{References}

Aben, I. F., Helderman, D. M., and Stammes, P.: Spectral finestructure in the polarization of skylight, Geophys. Res. Lett., 26, 591-594, 1999.

Boesche, E., Stammes, P., Ruhtz, T., Preusker, R., and Fischer, J.: Effect of aerosol microphysical properties on polarization of skylight: sensitivity study and measurements, Appl. Optics, 45, 8790-8805, 2006.

Boesche, E., Stammes, P., and Bennartz, R.: Aerosol influence on polarization and intensity in near-infrared $\mathrm{O}_{2}$ and $\mathrm{CO}_{2}$ absorption bands observed from space, J. Quant. Spectrosc. Ra., 110, 223-239, 2009.

Chandrasekhar, S.: Radiative transfer, Oxford University Press, London, UK, 1950.

Colarco, P. R., Schoeberl, M. R., Doddridge, B., Marufu, L. T., Torres, O., and Welton, J.: Transport of smoke from Canadian forest fires to the surface near Washington D.C.: Injection height entrainment and optical properties, J. Geophys. Res., 109, D06203, doi:10.1029/2003JD004248, 2004.

Corradini, S. and Cervino, M.: Aerosol extinction coefficient profile retrieval in the oxygen A band considering multiple scattering atmosphere Test case: SCIAMACHY nadir simulated measurements, J. Quant. Spectrosc. Ra., 97, 354-380, 2006.

Coulson, K. L.: Polarization and Intensity of Light in the Atmospherem A. Deepak Pub, Hampton, VA, USA, 1988.

Daniel, J. S., Solomon, S., Miller, H. L., Langford, A. O., Portmann, R. W., and Eubank, C. S.: Retrieving cloud information from passive measurements of solar radiation absorbed by molecular oxygen and $\mathrm{O}_{2}-\mathrm{O}_{2}$, J. Geophys. Res., 108, 4515, doi:4510.1029/2002JD002994, 2003.

Deschamps, P. Y., Breon, F. M., Leroy, M., Podaire, A., Bricaud, A., Buriez, J. C., and Seze, G.: The POLDER mission: Instrument characteristics and scientific objectives, IEEE, 32, 598615, doi:10.1109/36.297978, 1994.

Dubuisson P., Frouin, R., Dessailly, D., Duforêt, L., Léon, J. F., Voss, K., and Antoine, D.: Estimating the altitude of aerosol plumes over the ocean from reflectance ratio measurements in the $\mathrm{O}_{2}$ A-band, Remote Sens. Environ., 113, 1899-1911, 2009.

Fischer, J. and Grassl, H.: Detection of cloud-top height from backscattered radiances within the oxygen A band. Part 1: Theoretical study, J. Appl. Meteorol., 30, 1245-1259, 1991.

Fischer, J., Cordes, W., Schmitz-Peiffer, A., Renger, W., and Mörl, P.: Detection of cloud-top height from backscattered radiances within the oxygen A band. Part 2: Measurements, J. Appl. Meteorol., 30, 1260-1267, 1991.

Forster, P., Ramaswamy, V., Artaxo, P., Berntsen, T., Betts, R., Fahey, D. W., Haywood, J., Lean, J., Lowe, D. C., Myhre, G., Nganga, J., Prinn, R., Raga, G., Schulz, M., and Van Dorland, R.: Changes in atmospheric constituents and in radiative forcing. Climate Change 2007: The Physical Science Basis, edited by: Solomon, S., Qin, D. , Manning, M., Chen, Z., Marquis, M., Averyt, K. B. , Tignor, M., and Miller, H. L., Cambridge University Press, Cambridge, UK, 129-234, 2007.

Goody, R. M. and Yung, Y. L.: Atmospheric radiation: Theoretical basis (2nd edn.), Oxford University Press, New York, USA, 1989.

Grechko, Y. I., Dianov-Klokov, V. I., and Malkov, I. P.: Aircraft measurements of photon paths in reflection and transmission of light by clouds in the $0.76 \mathrm{~mm}$ oxygen band, Atmos. Ocean Phys., 9, 262-265, 1973.

Hanel, R. A.: Determination of Cloud Altitude from a Satellite, J. Geophy. Res., 66, 1300-1300, doi:10.1029/JZ066i004p01300, 1961.

Hansen, J. E. and Travis, L. D.: Light scattering in planetary atmospheres, Space Sci. Rev., 16, 527-610, 1974.

Harrison, L. and Min, Q.: Photon Pathlengths from $\mathrm{O}_{2}$ A-band Absorption. IRS '96: Current Problems in Atmospheric Radiation, Proc. Intl. Rad. Symposium 19-24 August 1996, Fairbanks, AK, USA, A. Deepak Press, Hampton, VA, USA, ISBN 0-93719439-5, 594-598, 1997.

Haywood, J. M. and Shine, K. P.: Multi-spectral calculations of the direct radiative forcing of tropospheric sulphate and soot aerosols using a column model, Q. J. Roy. Meteor. Soc., 123, 1907-1930, 1997.

Heidinger, A. K. and Stephens, G. L.: Molecular line absorption in a scattering atmosphere. Part II: Application to remote sensing in the $\mathrm{O}_{2}$ A band, J. Atmos. Sci., 57, 1615-1634, 2000.

Hovenier, J. W., van der Mee, C., and Domke, H.: Transfer of polarized light in planetary atmospheres-basic concepts and practical methods, Springer, Berlin, Germany, 2004.

Huang, J., Adams, A., Wang, C., and Zhang, C.: Black Carbon and West African Monsoon precipitation: observations and simulations, Ann. Geophys., 27, 4171-4181, doi:10.5194/angeo-274171-2009, 2009.

Hunt, W. H., Winker, D. M., Vaughan, M. A., Powell, K. A., Lucker, P. L., and Weimer, C.: CALIPSO Lidar Description and Performance Assessment, J. Atmos. Ocean. Tech., 26, 1214-1228, 2009.

IPCC: Climate Change 2013: The Physical Science Basis. Contribution of Working Group I to the Fifth Assessment Report of the Intergovernmental Panel on Climate Change, edited by: Stocker, T. F., Qin, D., Plattner, G.-K., Tignor, M., Allen, S. K., Boschung, J., Nauels, A., Xia, Y., Bex, V., and Midgley, P. M., Cambridge University Press, Cambridge, UK and New York, NY, USA, 1535 pp., doi:10.1017/CBO9781107415324, 2013.

Kahn, R. A., Li, W.-H., Moroney, C., Diner, D. J., Martonchik, J. V., and Fishbein, E.: Aerosol source plume physical characteristics from space-based multiangle imaging, J. Geophys. Res., 112 D11205, doi:11210.11029/12006JD007647, 2007.

Kessner, A., Wang, J., Levy, R., and Colarco, P.: Remote sensing of surface visibility from space: A look at the United States East Coast, Atmos. Environ., 81, 136-147, 2013.

Kokhanovsky, A. A. and Rozanov, V. V.: The physical parameterization of the top-of-atmosphere reflection function for a cloudy atmosphere-underlying surface system: the oxygen A-band case study, J. Quant. Spectrosc. Ra., 85, 35-55, doi:10.1016/S00224073(03)00193-6, 2004.

Koppers, G. A. A. and Murtagh, D. P.: Retrieval of height resolved aerosol optical thickness in the atmospheric band (Chapter 5), in: Radiative transfer in the absorption bands of oxygen: Studies of their significance in ozone chemistry and potential for aerosol remote sensing, edited by: Koppers, G. A. A., Stockholm University, Stockholm, Sweden, 1997.

Kuze A., Suto, H., Nakajima, M., and Hamazaki, T.: Thermal and near infrared sensor for carbon observation Fourier-transform spectrometer on the Greenhouse Gases Observing Satellite for 
greenhouse gases monitoring, Appl. Optics, 48, 6716-6733, 2009.

Levelt, P. F., van den Oord, G. H. J., Dobber, M. R., Mälkki, A., Visser, H., de Vries, J., Stammes, P., Lundell, J., and Saari, H.: The Ozone Monitoring Instrument, IEEE T. Geosci. Remote, 44, 1093-1101, doi:10.1109/TGRS.2006.872333, 2006.

Liu, Y., Wang, Z., Wang, J., Welton, E. J., Ferrare, R. A., and Newson, R. K.: The effect of aerosol vertical profiles on satelliteestimated surface particle sulfate concentrations, Remote Sens. Environ., 115, 508-513, 2011.

Maignan, F., Breon, F.-M., Fedele, E., and Bouvier, M.: Polarized refectances of natural surfaces: Spaceborne measurements and analytical modeling, Remote Sens. Environ., 113, 2642-2650, 2009

McClatchey, R. A., Fenn, R. W., Selby, J. E. A., Volz, F. E., and Garing, J. S.: Optical Properties of the Atmosphere, AFCRL TR700527, AD715270, 1970.

Meloni, D., di Sarra, A., Di Iorio, T. and Fiocco, G.: Influence of the vertical profile of Saharan dust on the visible direct radiative forcing, J. Quant. Spectrosc. Ra., 93, 397-413, 2005.

Meng, Z., Yang, P., Kattawar, G. W., Bi, L., Liou, K. N., and Laszlo, I.: Single-scattering properties of tri-axial ellipsoidal mineral dust aerosols: A database for application to radiative transfer calculations, J. Aerosol Sci., 41, 501-512, doi:10.1016/j.jaerosci.2010.02.008, 2010.

Min, Q. L., Harrison, L. C., Kierdron, P., Berndt, J., and Joseph, E.: A high-resolution oxygen A-band and water vapor band spectrometer, J. Geophys. Res., 109, D02202, doi:10.1029/2003JD003540, 2004.

Mitchell, R. M. and O'Brien, D. M.: Error estimates for passive satellite measurement of surface pressure using absorption in the A band of oxygen, J. Atmos. Sci., 44, 1981-1990, 1987.

O'Brien, D. M. and Mitchell, R. M.: Error estimates for retrieval of cloud-top pressure using absorption in the A-band of oxygen, $\mathrm{J}$. Appl. Meteorol., 31, 1179-1192, 1992.

Pfeilsticker, K., Erle, F., Funk, O., Veitel, H., and Platt, U.: First geometrical path lengths probability density function derivation of the skylight from spectroscopically highly resolving oxygen A-band observations. 1. Measurement technique atmospheric observations and model calculations, J. Geophys. Res., 103, 1148311504, 1998.

Preusker, R., Bottger, U., and Fischer, J.: Spectral and bidirectional measurements of the Stokes vector in the $\mathrm{O}_{2} \mathrm{~A}$ band and their interpretation, in: Atmospheric Sensing and Modeling II, edited by: Santer, R. P., Proceedings of SPIE, 2582, 13-20, 1995.

Rodgers, C. D.: Information content and optimisation of high spectral resolution measurements, in: Optical spectroscopic techniques and instrumentation for atmospheric and space research II, SPIE, 2830, 136-147, 1996.

Rodgers, C. D.: Inverse Methods for Atmospheric Sounding: Theory and Practice, World Scientific, Singapore, 2000.

Rothman, L. S., Gordon, I. E., Babikov, Y., Barbe, A., Benner, D. C., Bernath, P. F., Birk, M., Bizzocchi, L., Boudon, V., Brown, L. R., Campargue, A., Chance,, K., Coheni, E. A., Coudert L. H., Devi, V. M., Drouin, B. J., Fayt, A., Flaud, J.-M., Gamache, R. R., Harrison, J. J., Hartmann, J.-M., Hill, C., Hodges, J. T., Jacquemart, D., Jolly, A., Lamouroux, J. R., Le Ror, Li, J. G., Long, D. A., Lyulin, O. M., Mackie, C. J., Massie, S. T., Mikhailenko, S., Müller, H. S. P., Naumenko, O. V., Nikitin, A. V., and Or- phal, J.: The HITRAN 2012 molecular spectroscopic database, J. Quant. Spectrosc. Ra., 130, 4-50, 2013.

Samset, B. H. and Myhre, G.: Vertical dependence of black carbon sulphate and biomass burning aerosol radiative forcing, Geophys. Res. Lett., 38, L24802, doi:10.1029/2011GL049697, 2011.

Samset, B. H., Myhre, G., Schulz, M., Balkanski, Y., Bauer, S., Berntsen, T. K., Bian, H., Bellouin, N., Diehl, T., Easter, R. C., Ghan, S. J., Iversen, T., Kinne, S., Kirkevåg, A., Lamarque, J.F., Lin, G., Liu, X., Penner, J. E., Seland, Ø., Skeie, R. B., Stier, P., Takemura, T., Tsigaridis, K., and Zhang, K.: Black carbon vertical profiles strongly affect its radiative forcing uncertainty, Atmos. Chem. Phys., 13, 2423-2434, doi:10.5194/acp-13-24232013, 2013.

Sanghavi, S., Martonchik, J. V., Landgraf, J., and Platt, U.: Retrieval of the optical depth and vertical distribution of particulate scatterers in the atmosphere using $\mathrm{O}_{2} \mathrm{~A}$ - and B-band SCIAMACHY observations over Kanpur: a case study, Atmos. Meas. Tech., 5, 1099-1119, doi:10.5194/amt-5-1099-2012, 2012.

Satheesh, S. K., Torres, O., Remer, L. A., Babu, S. S., Vinoj, V., Eck, T. F., Kleidman, R. G., and Holben, B. N.: Improved assessment of aerosol absorption using OMI-MODIS joint retrieval, J. Geophys. Res., 114, D05209, doi:10.1029/2008JD011024, 2009.

Spurr, R.: VLIDORT: A linearized pseudo-spherical vector discrete ordinate radiative transfer code for forward model and retrieval studies in multilayer multiple scattering media, J. Quant. Spectrosc. Ra., 102, 316-342, 2006.

Spurr, R.: LIDORT and VLIDORT: Linearized pseudo-spherical scalar and vector discrete ordinate radiative transfer models for use in remote sensing retrieval problems, in: Light Scattering Reviews, edited by: Kokhanovsky, A. A., Springer, New York, USA, 3, 229-278, 2008.

Spurr, R. and Christi, M.: On the generation of atmospheric property Jacobians from the (V)LIDORT linearized radiative transfer models, J. Quant. Spectrosc. Ra., 142, 109-115, 2014.

Spurr, R. J. D.: A new approach to the retrieval of surface properties from earthshine measurements, J. Quant. Spectrosc. Ra., 83, 1546, 2004

Spurr, R., Wang, J., Zeng, J., and Mishchenko, M.: Linearized Tmatrix and Mie scattering computations, J. Quant. Spectrosc. Ra., 113, 425-439, 2012

Stam, D. M., De Haan, J. F., Hovenier, J. W., and Stammes, P.: Degree of linear polarization of light emerging from the cloudless atmosphere in the oxygen A band, J. Geophys. Res., 104, 1684316858, 1999.

Tanré, D., Bréon, F. M., Deuzé, J. L., Dubovik, O., Ducos, F., François, P., Goloub, P., Herman, M., Lifermann, A., and Waquet, F.: Remote sensing of aerosols by using polarized, directional and spectral measurements within the A-Train: the PARASOL mission, Atmos. Meas. Tech., 4, 1383-1395, doi:10.5194/amt-4-1383-2011, 2011.

Twomey, S.: The influence of pollution on the shortwave albedo of clouds, J. Atmos. Sci., 34, 1149-1152, 1977

van Diedenhoven, B., Hasekamp, O. P., and Landgraf, J.: Retrieval of cloud parameters from satellite-based reflectance measurements in the ultraviolet and the oxygen A-band, J. Geophys. Res., 112, D15208, doi:10.1029/2006JD008155, 2007.

Vasilkov, A., Joiner, J., and Spurr, R.: Note on rotational-Raman scattering in the $\mathrm{O}_{2}$ A- and B-bands, Atmos. Meas. Tech., 6, 981-990, doi:10.5194/amt-6-981-2013, 2013. 
Vaughan, M., Young, S., Winker, D., Powell, K., Omar, A., Liu, Z., Hu, Y., and Hostetler, C.: Fully automated analysis of spacebased lidar data: An overview of the CALIPSO retrieval algorithms and data products, Proc. SPIE Int. Soc. Opt. Eng., 5575, 16-30, 2004.

Wang, J., Liu, X., Christopher, S. A., Reid, J. S., Reid, E. A., and Maring, H.: The effects of non-sphericity on geostationary satellite retrievals of dust aerosols, Geophys. Res. Lett., 30, 2293, doi:10.1029/2003GL018697, 2003.

Wang, J., Nair, U., and Christopher, S. A.: GOES-8 Aerosol Optical thickness assimilation in a mesoscale model: Online integration of aerosol radiative effects, J. Geophys. Res., 109, D23203, doi:10.1029/2004JD004827, 2004.

Wang, J., van den Heever, S. C., and Reid, J.: A conceptual model for the link between Central American biomass burning aerosols and severe weather over the south central United States, Environ. Res. Lett., 4, 015003, doi:10.1088/1748-9326/4/1/015003, 2009.

Wang, J., Xu, X., Ding, S., Zeng, J., Spurr, R., Liu X., Chance, K., and Mishchenko, M.: A numerical testbed for remote sensing of aerosols and its demonstration for evaluating retrieval synergy from a geostationary satellite constellation of geo-cape and goes-r, J. Quant. Spectrosc. Ra., 146, 510-528, doi:10.1016/j.jqsrt.2014.03.020, 2014.
Winker, D.: Accounting for multiple scattering in retrievals from space lidar, Proc. SPIE Int. Soc. Opt. Eng., 5059, 128-139, 2003.

$\mathrm{Xu}, \mathrm{X}$. and Wang, J.: Retrieval of aerosol microphysical properties from AERONET photo-polarimetric measurements: 1. Information content analysis, J. Geophys. Res., 120, 7059-7078, 2015.

Xu, X., Wang, J., Zeng, J., Spurr, R., Liu, X., Dubovik, O., Li, L., Li, Z., Mishchenko, M. I., Siniuk, A., and Holben, B. N.: Retrieval of aerosol microphysical properties from AERONET photopolarimetric measurements: 2. A new research algorithm and case demonstration, J. Geophys. Res., 120, 7079-7098, 2015.

Yamamoto, G. and Wark, D. Q.: Discussion of the Letter by R. A. Hanel, Determination of Cloud Altitude from a Satellite, J. Geophy. Res., 66, p. 3596, 1961.

Zarzycki, C. M. and Bond, T. C.: How much can the vertical distribution of black carbon affect its global direct forcing?, Geophys. Res. Lett., 37, L20807, doi:10.1029/2010GL044555, 2010.

Zeng, J., Han, Q., and Wang, J.: High-spectral resolution simulation of polarization of skylight: Sensitivity to aerosol vertical profile, Geophys. Res. Lett., 35, L20801, doi:10.1029/2008GL035645, 2008. 